\title{
Violência e Saúde: uma análise da produção científica publicada em periódicos nacionais entre 2003 e 2007
}

I ${ }^{1}$ Daniela Tavares Gontijo, ${ }^{2}$ Heliana Castro Alves, ${ }^{3}$ Michelle Helena

Pereira de Paiva, ${ }^{4}$ Ruth Maria Ribeiro Guerra, ${ }^{5}$ Verônica Borges Kappel I

Resumo: A violência, atualmente entendida como um dos maiores problemas de saúde pública mundial e cuja magnitude cresce vertiginosamente, tem sido alvo de discussões e intervenções que se explicitam tanto nos debates cotidianos da mídia, quanto nas produções divulgadas nos meios acadêmico e científico. Considerando a velocidade crescente da produção e divulgação do conhecimento científico e a necessidade de se aprofundar a discussão do fenômeno na realidade brasileira, neste trabalho objetivou-se analisar a produção científica publicada em periódicos nacionais da área da saúde sobre o tema violência e saúde de 2003 a 2007. Os dados foram coletados na base de dados LILACS e sistematizados em um protocolo no qual foram alocadas as variáveis de estudo. $\mathrm{O}$ processo de análise de dados, realizado através da estatística descritiva e análise de conteúdo na modalidade temática, possibilitou a constatação da pulverização do estudo sobre a violência nos periódicos da saúde, principalmente naqueles direcionados para a saúde pública. A partir de diferentes tipos e abordagens de pesquisa, os autores direcionaram sua atenção para o estudo de temáticas relacionadas às Construções Teórico-Metodológicas; Violência e Gênero; Violência e Infância e Adolescência; Violência contra Idosos; e Violência em Situações Específicas. Foi possível identificar, no período estudado, lacunas na produção do conhecimento em saúde sobre a violência direcionada a grupos especialmente vulneráveis ao fenômeno, bem como sobre a análise da efetividade de estratégias de enfrentamento.

> Palavras-chave: violência, saúde, avaliação da pesquisa em saúde.

\author{
1 Professora adjunta do Curso \\ de Terapia Ocupacional da \\ Universidade Federal do \\ Triângulo Mineiro (UFTM) \\ Endereço eletrônico: daniela@ \\ uftm.edu.br \\ 2 Professora assistente do \\ Curso de Terapia Ocupacional \\ da Universidade Federal do \\ Triângulo Mineiro (UFTM). \\ ${ }^{3}$ Graduanda em Terapia \\ Ocupacional na Universidade \\ Federal do Triângulo Mineiro \\ (UFTM). \\ ${ }^{4}$ Graduanda em Terapia \\ Ocupacional na Universidade \\ Federal do Triângulo Mineiro \\ (UFTM). \\ ${ }^{5}$ Graduanda em Terapia \\ Ocupacional na Universidade \\ Federal do Triângulo Mineiro \\ (UFTM).
}


A violência sempre fez parte da experiência humana, sendo que seus efeitos podem ser vistos em todas as partes do mundo. A cada ano, mais de 1,6 milhôes de pessoas perdem a vida e muitas sofrem lesões decorrentes da violência autoinfligida, interpessoal ou coletiva (KRUG et al., 2002). Entendida enquanto um dos maiores problemas de saúde pública mundial, cuja magnitude cresce vertiginosamente, a ocorrência da violência, seu impacto na saúde, bem como as estratégias de prevenção têm sido priorizados como alvo de discussões e intervenções que se explicitam tanto nos debates cotidianos da mídia de uma forma geral, quanto nas produçoes divulgadas no meio acadêmico e científico.

Considerando as graves consequências da violência, em curto e em longo prazo, para os indivíduos, as famílias, as comunidades e os países, a Organização Mundial de Saúde definiu como uma de suas prioridades a caracterização dos diferentes tipos de violência, de suas causas, bem como o dimensionamento de sua magnitude, entendendo essas informações como vitais para o enfrentamento do problema, principalmente a partir de um enfoque preventivo. Nesta direção, em 2002 foi divulgado o Relatório Mundial sobre Violência e Saúde (KRUG et al., 2002), que contou com a colaboração de mais de 160 especialistas do mundo inteiro. Nesse relatório, a violência é definida como "o uso intencional da força física ou do poder, real ou ameaça, contra si próprio, contra outra pessoa, ou contra um grupo ou uma comunidade, que resulte ou tenha grande possibilidade de resultar em lesão, morte, dano psicológico, deficiência de desenvolvimento ou privação" (KRUG et al., 2002, p. 5).

Inicialmente, Krug et al. (2002) propõem uma tipologia para a compreensão da violência a partir do reconhecimento de quem comete o ato violento. É possível identificar a violência autoinfligida, a interpessoal e a coletiva, que podem envolver atos de natureza física, psicológica, sexual ou de negligência e privações. Em sua estruturação, o relatório a partir do referencial ecológico discute o fenômeno da violência de forma específica, em relação à juventude, ao abuso e negligência de crianças por pais e cuidadores, à violência física cometida por parceiros, à violência sexual, ao abuso na velhice, à violência autoinfligida e finalmente à violência coletiva.

De uma forma geral, o Relatório Mundial sobre Violência e Saúde aponta que a violência se caracteriza como um fenômeno previsível e passível de prevenção, cujo 
enfrentamento perpassa o investimento adequado, a compreensão do contexto no qual ocorre, bem como as relações estabelecidas entre este e os diferentes tipos de violência, pelo combate ao processo de naturalização e banalização dessa violência na vida cotidiana e pela elaboração e implantação de políticas públicas efetivas.

Especificamente, em relação ao setor saúde, Krug et al. (2002) apontam a necessidade de uma tomada de responsabilização deste em relação à violência, sobretudo em virtude da presença deste fenômeno na rotina dos serviços, que perpassa o reconhecimento do problema até o cuidado efetivo de suas vítimas. Além disso, o setor da saúde é chamado a assumir papel proativo na prevenção da violência, de forma articulada com outros setores da sociedade.

Considerando a velocidade crescente da produção e divulgação do conhecimento científico e a necessidade de se aprofundar a discussão do fenômeno na realidade brasileira, neste trabalho objetivou-se analisar a produção científica publicada em periódicos nacionais da área da saúde sobre o tema violência e saúde nos períodos de 2003 a 2007. Através desta análise, que permite identificar e compreender saberes consolidados e emergentes, esperamos contribuir para a explicitação de aspectos relacionados tanto à magnitude quanto aos processos de legitimação dos debates acerca do fenômeno em estudo, bem como para a construção de um cenário teórico e metodológico que possa auxiliar nas intervenções dos profissionais de saúde.

\section{Metodologia}

De acordo com Gomes e Nascimento (2006), há inúmeros caminhos para se refletir sobre a produção do conhecimento acerca de determinado tema. Neste trabalho, optou-se por uma aproximação da revisão crítica da literatura, uma vez que só foram analisados os resumos dos textos em virtude da grande quantidade de informações. A revisão crítica de literatura proporciona uma síntese do conhecimento baseado em pesquisas, possibilitando a identificação de lacunas do conhecimento e áreas que necessitam de futuras pesquisas para a elaboração de estratégias de enfrentamento da violência.

O estudo foi realizado na base de dados Literatura Latino-Americano e do Caribe em Ciências da Saúde (LILACS) da Bireme, sendo coletados os resumos de artigos científicos, publicados em periódicos brasileiros, no período de 2003 a 2007. A busca foi realizada utilizando os seguintes descritores que abrangem 
todos os termos cadastrados na base de dados relacionados ao tema: violência, violência baseada em gênero, violência doméstica, violência doméstica e sexual contra a mulher, violência sexual, violência contra a mulher, violência de gênero, violência na família. Foram excluídas as publicações classificadas como teses, capítulos de livros, livros, guias médicos, comentários, resenhas, informativos governamentais, artigos sem resumos e aqueles publicados em outros países.

Inicialmente, os dados foram sistematizados em um protocolo elaborado pelas pesquisadoras, no qual foram alocadas as seguintes variáveis de estudo: autores, periódico, área científica do periódico, ano, título, objetivo do estudo, tipo de pesquisa, abordagem metodológica-sujeitos, método de coleta, método de análise e resultados. As variáveis autores, revista, área científica da revista, tipo de pesquisa, sujeitos, método de coleta e método de análise foram submetidos à análise estatística descritiva (frequência absoluta e relativa) com auxílio do programa Excel for Windows Microsoft. As variáveis título, objetivo e resultados foram analisados através da utilização da técnica de análise de conteúdo temática proposta por Bardin (1979).

O processo de análise resultou em cinco categorias temáticas, que embora descritas de forma isolada, articulam-se para a compreensão da complexidade do fenômeno. No processo de categorização, os estudos foram divididos em três grandes grupos a partir do enfoque dado pelos autores. Os estudos que se direcionaram para a discussão no campo teórico acerca da violência foram alocados na categoria Construçôes Teórico-Metodológicas. Os estudos que abordaram o fenômeno considerando um grupo social específico, a partir de critérios como gênero e idade constituíram a categoria Violência e Gênero; Violência e Infância e Adolescência e Violência contra Idosos. Finalmente, os estudos que discutem a violência com enfoque em situações nas quais estes ocorrem, e não especificamente em relação a uma população, foram alocados na categoria Violência e Situaçōes Especificas.

\section{Resultados e discussão}

O processo de coleta de dados a partir dos descritores citados inicialmente resultou em 2.782 publicações. Destas, 2.391 foram excluídas do estudo de acordo com os critérios de exclusão já explicitados. Assim, neste trabalho foram analisados os resumos de 391 artigos, publicados por 841 autores, no período de 2003 a 2007. 
O ano de 2003 correspondeu a 17,13\% das publicações; o ano de 2004, a 17,90\%; o ano de 2005 correspondeu a 23,01\%. O ano de 2006 teve o maior número de publicações, com 23,27\%, sendo que em 2007 encontraram-se 18,67\%.

Os artigos foram publicados em 108 periódicos, sendo que 110 artigos $(28,13 \%)$ foram publicados em revistas que têm como área científica privilegiada a saúde pública, refletindo a caracterização e apropriação da temática violência neste setor como uma questão de saúde pública.

Para abordar o assunto, os autores utilizaram diferentes métodos de pesquisa, sendo encontradas 118 pesquisas bibliográficas, 192 pesquisas de campo e 46 pesquisas documentais; em 35 resumos não foi possível identificar o método de pesquisa adotado. A adoção de diferentes métodos de pesquisa reflete o caráter multifacetado e complexo do fenômeno em estudo, que traz em si a necessidade de diferentes formas de abordagem para sua compreensão, desde reflexões a partir de conteúdos essencialmente teóricos até o diálogo deste referencial com dados empíricos coletados a partir da realidade dos sujeitos sociais.

Especificamente em relação às pesquisas de campo, as coletas de dados foram realizadas com diferentes sujeitos, demonstrando uma pulverização do fenômeno na sociedade. No entanto, observa-se uma frequência elevada $(22,5 \%)$ de estudos direcionados para a realidade das mulheres e crianças e adolescentes (30,94\%), o que vai ao encontro dos resultados apresentados pelo Relatório Mundial sobre Violência e Saúde (KRUG et al., 2002), que aponta a necessidade de discutir o fenômeno a partir de grupos considerados mais vulneráveis, especialmente considerando gênero e faixa etária (sobretudo crianças e idosos). É importante pontuar o pequeno número de estudos direcionados para a análise da violência a partir da caracterização e perspectiva dos agressores.

Ainda em relação às pesquisas de campo, observa-se a utilização de diferentes métodos de coleta de dados, sendo a entrevista, em suas diferentes formas, o método mais relatado $(54,33 \%)$. Um aspecto que chama a atenção nos resumos analisados é a ausência, em 55 estudos, que corresponde a 28,79\% deste tipo de pesquisa, da informação referente ao método de coleta de dados utilizado. A ausência de informaçôes no resumo referentes ao percurso metodológico adotado pelos pesquisadores também se refletiu na variável método de análise de dados.

Embora a análise específica dos aspectos metodológicos envolvidos na construção das pesquisas científicas não seja objetivo principal deste trabalho, uma 
vez que este foi estruturado a partir da leitura somente dos resumos dos textos, é importante considerar a necessidade de uma maior atenção, dos pesquisadores e revisores dos periódicos, para a estruturação deste item no artigo, uma vez que estes são uma espécie de "carta de apresentação" da pesquisa, a partir do qual leitores e outros pesquisadores optam ou não pela leitura do trabalho completo.

A partir da análise das variáveis título, objetivos e resultados, foi possível construir categorias temáticas que permitiram a reflexão e discussão dos temas que emergiram dos referidos conteúdos, considerando todos os tipos de pesquisa (bibliográfica documental e de campo).

$\mathrm{Na}$ categoria Construçôes Teórico-Metodológicas, que corresponde a 14,06\% dos artigos, foram alocados os estudos que se direcionam especificamente para a elaboração e discussão de referenciais teóricos que buscam explicar o fenômeno da violência, as relações entre bioética e violência, bem como a criação, sistematização e avaliação de instrumentos para sua mensuração (quadro I).

Em relação às estruturas conceituais, não foi possível identificar uma consensualidade sobre o fenômeno nos resumos que abordam diretamente o assunto. Neste sentido, durante o processo de análise se destacam as construções a partir do referencial psicanalítico (GIROLA, 2004; SANTI, 2004; CASTELO FILHO, 2006; BARROS, 2006), bem como uma aproximação com o conceito proposto pela OMS discutido anteriormente (NARVAZ; KOLLER, 2006; NEVES; ROMANELLI; 2006; GOMES et al., 2007).

Alguns autores discutem a trajetória histórica da criminalidade na realidade brasileira (PEIXOTO; LIMA; DURANTE, 2004), enquanto outros direcionam sua atenção para a construção e ou adaptação transcultural de instrumentos de mensuração da violência (AVANCI et al. 2005; REICHENHEIM; MORAES, 2003; GRASSI-OLIVEIRA; STEIN; PEZZI, 2006; REICHENHEIM; MORAES, 2006). Os estudos de desenvolvimento e validação de instrumentos de mensuração da violência são de extrema importância, uma vez que sua utilização fornece dados que podem subsidiar o planejamento e avaliação da efetividade de estratégias de enfrentamento do fenômeno em âmbito individual, social ou comunitário.

Ainda nesta categoria, foram alocados os estudos que discutem conceitualmente as relações entre alguns fatores e a violência, como uso de substâncias psicoativas, sobretudo o álcool (MELONI; LARANJEIRA, 2004; CHALUB; TELLES, 
2006) e a presença doenças mentais (VALENÇA MORAES, 2006). De uma

forma geral, de acordo com o Relatório Mundial sobre Violência e Saúde, o álcool é um importante fator situacional que pode precipitar a violência, sendo que a disponibilidade da substância e os índices de criminalidade possuem relação direta de proporcionalidade. Por outro lado, a associação entre doença mental e violência não está totalmente esclarecida, sendo sua percepção também influenciada por concepções historicamente construídas.

Finalmente, nesta categoria, são discutidos aspectos relacionados à bioética, nos quais se destacam a necessidade de maior aproximação entre esta e a violência, uma vez que a violência está relacionada diretamente aos conceitos de maleficência e autonomia (BRAZ, 2004; FORTES, 2004).

$\mathrm{Na}$ categoria Violência contra idosos, encontram-se apenas quatro artigos $(1,02 \%)$ que abordam a problemática (quadro II). Segundo Santos et al. (2007), a violência contra o idoso é alarmante e ocorre na grande maioria das vezes no âmbito familiar. De acordo com esse autor, a violência é um fenômeno complexo, multifacetado e dinâmico de difícil controle, até mesmo em países com alto nível de qualidade de vida.

A escassez de publicações sobre a extensão de maus-tratos à população idosa não significa que este problema está terminando; pelo contrário, este tipo de violência está disseminado e presente na sociedade mais do que os dados epidemiológicos podem e conseguem revelar (KRUG et al., 2002). Vale ressaltar que os idosos são pessoas vulneráveis, sobretudo no caso de incapacidades, e à medida que vão se tornando mais dependentes de seus familiares ou cuidadores, vão ficando cada vez mais sujeitos a abusos, principalmente o econômico. A situação de violência sofrida por idosos, no Brasil, alcançou maior visibilidade e se tornou pauta das políticas sociais a partir de 2003, com a promulgação do Estatuto do Idoso.

A violência sofrida pelas mulheres nas relações conjugais, que ocorrem principalmenteno ambiente doméstico, éalvo de discussão de muitos pesquisadores. Nessas pesquisas se destacam os estudos que abordam as diferentes variáveis associadas à violência, como concepções hegemônicas de gênero (RAMÃO; MENEGHEL; OLIVEIRA, 2005; BLAY, 2003), baixa renda e escolaridade, consumo de drogas, ausência de diálogo e violência na família (RABELLO; CALDAS, 2007; ROLDÁN; GALERA; O’BRIEN, 2005; GUARESCHI et al., 2006; ALVIM; SOUZA, 2005; GOMES; FREIRE, 2005; ALVES; DINIZ, 

2007; DOUBOVA et al., 2007); as possíveis consequências da violência como o aumento do índice de morbi-mortalidade (VAIZ; NAKANO, 2004; DINIZ et al., 2007); a questão da violência na gestação e no parto (MENEZES et al., 2003; CASTRO; RUÍZ, 2004; MATTAR et al., 2007).

A terceira categoria em discussão refere-se à Violência e Gênero e abrange conteúdos relacionados à violência contra homossexuais, violência conjugal/ doméstica, violência e saúde da mulher e estratégias de enfrentamento da violência contra a mulher, representando $23,27 \%$ dos artigos analisados (quadro III).

A violência contra homossexuais, discutida em três artigos, caracteriza-se como um tema relacionado intrinsecamente a socializaçōes de gênero, envolto por silêncio tanto por parte da sociedade mais ampla, quanto pelo movimento homossexual (NUNAN, 2004). A pouca visibilidade existente acerca da violência doméstica contra homossexuais, de acordo com Carrana e Vianna (2006), pode estar relacionada a fatores como preconceito, envolvimento com drogas, prostituição e estigmatização social, o que culmina em poucas situaçôes notificadas e limitados serviços de atendimento e acolhimento adequados a essas pessoas.

Diversos estudos caracterizam e discutem o perfil de mulheres agredidas (ADEODATO et al., 2005; GARBIN et al., 2006; MOTA; VASCONCELOS; ASSIS, 2007; RABELLO; CALDAS JÚNIOR, 2006; REZENDE et al., 2007; GALVÃO; ANDRADE, 2004; LOPES et al., 2004; OSHIKATA; BEDONE; FAÚNDES, 2005; OLIVEIRA; CARVALHO, 2006; OLIVEIRA; FONSECA, 2007; DINIZ et al., 2007; BEDONE; FAÚNDES, 2007). No entanto, apesar de não ser possível traçar um perfil característico, uma vez que a violência acomete mulheres de todas as idades e classes sociais, observa-se uma tendência dos estudos em buscar relações da violência com a escolaridade, estado civil, número de filhos, faixa etária e região geográfica de moradia. Além disso, os estudos buscam caracterizar a tipologia da violência contra a mulher sendo identificada maior frequência de violência psicológica e física (ALDRIGHI, 2004; SCHRAIBER et al., 2007; KRONBAUER; MENEGHEL, 2005; SILVA, 2003; MARINHEIRO; VIEIRA; SOUZA, 2006; SCHRAIBER et al., 2007).

Ainda em relação à violência contra a mulher, observa-se a caracterização dos serviços de atendimento às vítimas, mas são poucos os estudos que têm como objetivo principal apresentar, efetivamente, estratégias validadas de enfrentamento 
do problema. Nesses estudos as estratégias, em sua maioria, direcionadas para mulheres vitimas de violência sexual, apontam a utilização de oficinas e a necessidade de maior divulgação e estruturação dos serviços especializados para a população em geral, de implantação de práticas intersetoriais e de uma melhor qualificação profissional para lidar com o problema (BRANDÃO, 2006; MENEGHEL; INIIGUEZ, 2007; MACHADO, 2004; COELHO, 2005; OLIVEIRA et al., 2005; FREITAS; LIMA; DYTZ, 2007; VILLELA; LAGO, 2007). Finalmente, quando se discute a intervenção direcionada a estas mulheres, em dois resumos são destacadas as formas como profissionais e gestores lidam com os casos de violência de gênero (CAVALCANTI; GOMES; MINAYO, 2006; EIZLRIK et al., 2007).

A violência de gênero acomete principalmente o sexo feminino e constitui um desrespeito aos direitos humanos, além de ser uma questão de saúde pública. É importante ressaltar a ausência de estudos que discutem o perfil de perpetradores desta tipologia de violência, bem como a compreensão do fenômeno a partir do ponto de vista destes, sobretudo no que se refere às relações entre violência e masculinidades. Este aspecto é de vital importância, uma vez que se compreendem as relações de gênero como relações de poder socialmente constituídas entre homens e mulheres, nas quais as diferenças de sexo são apropriadas e transformadas em desigualdades (LOURO, 1999).

A masculinidade, ou masculinidades, são definidas por Gomes (2008, p. 70) como um "espaço simbólico que serve para estruturar a identidade de ser homem, modelando atitudes, comportamentos e emoções a serem adotados", sendo a concepção hegemônica deste espaço, em nosso contexto, caracterizada pela heterossexualidade e pela dominação. Neste sentido, Schraiber et al. (2009) apontam que a violência de gênero pode expressar a tentativa do homem de reconquista de poder perdido ou de prevenção desta perda nas situações em que esta dominação tradicional se encontra ameaçada. Assim sendo, o enfrentamento da violência contra a mulher implica desconstrução de normas sociais e padrões culturais, tanto de homens quanto de mulheres, que confirmam, autorizam, naturalizam e banalizam a dominação masculina sobre a mulher.

$\mathrm{Na}$ categoria Violência e Infância e Adolescência (quadro IV), encontramos a maior frequência de estudos (30,94\%), o que reflete maior preocupação social e acadêmica sobre o tema, fato também observado por Krug et al. (2002). De 
uma forma geral, os artigos buscam caracterizar o fenômeno da violência contra crianças e adolescentes e praticados por adolescentes, seus fatores condicionantes e consequências, bem como as estratégias de enfrentamento do problema.

No que se refere à caracterização da violência contra crianças e adolescentes, muitos estudos apontam sua ocorrência no contexto doméstico e intrafamiliar. Em geral, os estudos apontam familiares próximos como principais agressores (CAVALCANTI; DUARTE, 2004; VIEIRA et al., 2004; DELFINO; BIASOLI-ALVES; SAGIM, 2005) e discutem os fatores da dinâmica familiar relacionados à violência (ROSA; TASSARA, 2003; ROSA, TASSARA, 2004; CAVALCANTI; DUARTE, 2004; VIEIRA et al., 2004; DELFINO; BIASOLI-ALVES; SAGIM, 2005; BRITO et al., 2005; VASCONCELOS; SOUZA, 2006; SUÁREZ; MENKES, 2006; ROCHA; FERREIRA, 2006; SANTOS; FERRIANI, 2007). A violência física no ambiente doméstico é considerada o tipo de violência mais frequente contra crianças (BRITO et al., 2005; VASCONCELOS; SOUZA, 2006), sendo as mulheres as principais agressoras, enquanto a violência sexual é a forma mais comum contra adolescentes no contexto intrafamiliar (CESCA, 2004; FLORES; SCHIRMER, 2006).

Esses achados são similares aos encontrados por Krug et al. (2002), que apontam que, de maneira geral, as crianças menores estão mais suscetíveis aos maus-tratos físicos, enquanto as taxas mais elevadas de violência sexual encontram-se entre crianças que já atingiram a puberdade ou adolescência. Segundo os autores do Relatório, pesquisas sugerem em muitos locais que as mulheres utilizam mais castigos físicos do que os homens - provavelmente por estarem mais tempo com as crianças. Entretanto, quando a violência física provoca ferimentos graves ou fatais, é mais frequente que os agressores sejam os homens.

O enfoque específico na violência sexual infantil foi a escolha de Santos e Costa (2004); Ferriani, Garbin e Ribeiro (2004); Ribeiro, Ferriani e Reis (2004); Beraldo, Capitão e Oliveira (2006); Rodrigues, Brino e Williams (2006); Habigzang et al (2006) e Aded, Dalcin e Cavalcanti (2007). De uma forma geral, a maioria das vítimas é do sexo feminino, e os agressores, em sua maioria, são do sexo masculino, com menos de 20 anos, pai ou padrasto da vítima, residindo com a mesma e com a mãe da vítima.

Além da caracterização da violência contra crianças e adolescentes, os autores discutem as consequências físicas e psicológicas destes atos para as vítimas. 
De acordo com Salcedo e Carvalho (2005), é alto o índice de traumatismos crânio-encefálicos relacionados a episódios de violência na infância, assim como de outros tipos de traumatismos na região da face (CAVALCANTI; DUARTE, 2003; CHAIM; DARUGE; GONÇALVES, 2004; ANDRADELIMA; COLARES; CABRAL, 2005; CHAIM; GONÇALVES, 2006). Além disso, o impacto da violência na saúde emocional de crianças e adolescentes traz consequências importantes para seu desenvolvimento, sendo relacionado ao pior desempenho social e escolar (BRANCALHONE; FOGO; WILLIANS, 2004; BERALDO; CAPITÃO; OLIVEIRA, 2006; LOPES NETO, 2005; FENSTERSEIFER; BRAGA, 2003).

Embora existam poucos dados confiáveis acerca dos homicídios contra crianças e/ou adolescentes, sabe-se que as taxas de infanticídio entre crianças até quatro anos são mais que o dobro que as taxas encontradas em crianças de 5 a 14 anos. A principal causa de mortalidade é o traumatismo craniano, seguida de ferimentos abdominais e asfixia intencional (KRUG et al., 2002). As consequências da violência contra esta população são vastas do ponto de vista emocional, quando não existe fatalidade. Em geral, as vítimas têm mais dificuldade de aprendizagem, distúrbios de comportamento, isolamento social, atitudes erotizadas precoces, baixa autoestima, depressão e dificuldade para estabelecer relações sociais.

O abuso psicológico, característico quando os adultos depreciam as crianças, bloqueiam seus esforços de autoafirmação e as ameaçam de abandono e crueldade, está intimamente ligado a distúrbios do crescimento e do desenvolvimento psicomotor, social e intelectual. Um ambiente de submissão e humilhação pode maximizar sintomas de hiperatividade, agressividade, passividade e ainda elevar as dificuldades de lidar com a sexualidade (MINAYO, 2006). Além da violência citada acima, a negligência representa a omissão em relação à proteção integral, podendo levar à reincidência de internaçôes, acidentes domésticos, inadequação do nível de escolaridade à idade cronológica, absenteísmo da escola, falta de atenção e de limites mediante situações do cotidiano.

Especificamente em relação ao contexto escolar, o bullying é alvo de discussão de alguns autores (BRINGIOTTI; KRYUVELUK; LASSO, 2004; LOPES NETO, 2005; OLIVEIRA; ANTONIO, 2006), sendo pontuado por estes que o fenômeno é frequentemente ignorado por adultos. Sabe-se, porém, que a prática deste tipo de violência pode ter consequências negativas imediatas e tardias para 
todas as crianças/adolescentes. As ações características do bullying são verdadeiros atos de intimidação preconcebidos, ameaças que, sistematicamente, com violência física e psicológica, são repetidamente impostos a indivíduos mais vulneráveis e incapazes de se defenderem, o que os leva a uma condição de sujeição, sofrimento psicológico, isolamento e marginalização (OLIVEIRA; ANTÔNIO, 2006).

Em curto prazo, o bullying traumatiza o psiquismo de suas vítimas, provocando um conjunto de sinais e sintomas muito específicos, caracterizando uma síndrome denominada "Síndrome dos Maus-Tratos Repetitivos" (OLIVEIRA; ANTÔNIO, 2006). Além desta síndrome, o fenômeno pode afetar a autoestima e desencadear problemas severos como a anorexia, bulimia, depressão, ansiedade e suicídio nas vítimas. Em longo prazo, sabe-se que jovens afetados pelo bullying podem vir a se tornar adultos com saúde mental desequilibrada, podendo ser desencadeados, dentre outros, transtorno do pânico e crises de ansiedade, e quando não, autoextermínio ou homicídios cometidos pelos mesmos (OLIVEIRA; ANTÔNIO, 2006).

Entre os estudos que fizeram parte desta pesquisa, cinco discutem a violência praticada por adolescentes. De acordo com Priuli e Moraeso (2007), o perfil sociodemográfico, infracional e relacional de parte significativa dos adolescentes internados com 17 anos de São José do Rio Preto, se caracterizava por ensino fundamental incompleto, evadido da escola, sem trabalho, de menor poder socioeconômico. A infração de maior percentual foi roubo, seguida de furto, tentativa de homicídio, homicídio, roubo qualificado, tráfico de drogas e latrocínio. A maioria dos jovens usava tabaco, maconha, álcool e crack. Detectou-se uma realidade precária de familiares com baixo nível de renda, escolaridade, profissão e abuso de álcool, contribuindo para transformar os adolescentes em vítimas. A maioria das mães, provedora do lar, é a principal figura na internação dos adolescentes e a mediadora entre o adolescente, o Poder Judiciário e a comunidade.

De acordo com o Relatório Mundial sobre Violência e Saúde (KRUG et al., 2002), o problema da violência praticada por adolescentes não pode ser considerado de forma isolada de outros contextos. Problemas como vadiagem, abandono da escola, mentira compulsiva e abuso de substâncias lícitas e ilícitas são fatores que podem aumentar o índice de violência entre os jovens. Porém, nem todos com as características citadas serão necessariamente violentos. Além da análise do cometimento de atos infracionais por adolescentes, de forma geral, Krug et al. (2002) buscam entender as relações entre a experiência de vida nas ruas 
e a violência, com especial atenção para o trabalho infanto-juvenil, o alojamento

em instituições de privação de liberdade e a prostituição juvenil neste contexto. Estas situações podem potencializar o risco de violência contra e praticada por criança e/ou adolescente.

Não existe um fator isolado que explique a razão de uma pessoa se comportar de maneira violenta e outra não. A violência é um fenômeno extremamente complexo, que tem suas raízes na inter-relação de vários fatores: biológicos, econômicos, culturais, políticos e sociais. O Relatório Mundial sobre Violência e Saúde (KRUG et al., 2002) aplica um modelo ecológico para tentar compreender a natureza diversa da violência, separando os fatores que influenciam no comportamento em quatro níveis: individual; relações estreitas; contextos comunitários; e sociedade.

A participação em comportamentos delinquentes ou violentos antes dos 13 anos tem um fator individual importante, juntamente com impulsividade, atitudes ou crenças agressivas, e fracos resultados escolares. Duros castigos físicos ou presença de violência no lar, falta de controle e supervisão por parte dos pais e possuir amizades delinquentes são fatores relacionais importantes. Nos níveis comunitários e sociais, existem estudos que sugerem que a exposição da violência através da mídia produz aumentos em curto prazo nas agressões, além de que crianças e jovens serem importantes consumidores da mídia (KRUG et al., 2002).

Em outra direção, diversos estudos como os desenvolvidos por Fensterseifer e Braga (2003); Vagostello et al. (2003); Noguchi, Assis e Santos (2004); Gomes e Fonseca (2005); Azambuja (2005); Paixão e Deslandes (2005); Schwanck et al. (2005); Cunha, Assis e Pacheco (2005); Pires e Miyazaki (2005); Cardoso, Santana e Ferriani (2006); Granville-Garcia et al. (2006); Algeri e Souza (2006); e Grudtner e Carraro (2007) abordam questôes sobre percepção de violência contra crianças e adolescentes por parte dos profissionais da saúde (sendo a maioria da área de enfermagem) e a questão da notificação. Estes apontam que, de forma geral, há dificuldade destes profissionais para identificar as vítimas, sobretudo decorrentes da negligência e violência psicológica.

Finalmente, um último aspecto discutido nesta categoria se refere às estratégias de enfrentamento da violência contra crianças e adolescentes abordadas, por exemplo, por D’Affonseca e Williams (2003); Pizzetti (2006); Brasil et al. (2003) e Vendrúscolo et al. (2004). Em geral, os estudos referem à adoção de estratégias 
1030 de aumento da autoestima, bem como a necessidade de integração dos diversos serviços existentes e seus profissionais para promover intervenção nos problemas que crianças e adolescentes vêm sofrendo com o crescimento da violência em diversas áreas. Conforme pontuado por Brasil et al. (2003, p. 96): "em situações sociais complexas, envolvendo crianças e adolescentes em situação de risco, não existe um único modelo de intervenção possível, ao contrário, necessita-se de uma metodologia de intervenção particular que atenda às características peculiares desta população".

Entre as estratégias citadas, destacam-se neste contexto tanto as intervenções individuais quanto as grupais. As intervenções clínicas baseiam-se em psicoterapia de grupo com crianças vítimas de violência intrafamiliar e grupo de orientação interdisciplinares direcionados aos pais. Os estudos em geral apontam, assim como Minayo (2006), a necessidade de aquisição de maiores conhecimentos por parte dos profissionais da educação e da saúde, a fim de que se tornem habilitados para diagnosticar e enfrentar problemas trazidos pelas crianças e/ou adolescentes nos variados contextos em que estes sujeitos estão inseridos: escola, comunidade, serviços de saúde, entre outros.

Embora sejam promissoras as expectativas com relação à redução da violência contra criança e/ou adolescente, sabe-se que ainda são necessárias a execução efetiva de ações de prevenção e atendimento especializado, bem como a melhoria do diálogo entre os diversos órgãos envolvidos na questão (Conselho Tutelar, Polícia Civil, Instituições públicas e privadas, escolas, entre outros). Além disso, é importante salientar o envolvimento ativo dos meios de comunicação e da sociedade civil na divulgação e esclarecimento acerca dos órgãos destinados a atender os casos de violência contra criança e/ou adolescente.

$\mathrm{Na}$ categoria Violência em Situaçôes Específicas, foram alocados 30,68\% dos estudos que se direcionam para a análise do fenômeno em contextos e situaçôes específicas (quadro V). Nesses estudos, o enfoque é na caracterização das situaçôes e contextos nos quais ocorre a complexidade do fenômeno da violência, sem se direcionar, especificamente, conforme abordado nas categorias anteriores, a um grupo específico no que se refere a gênero ou faixa etária. Neste sentido, são discutidos assuntos relacionados à violência no mundo do trabalho, no trânsito, no contexto familiar, institucional, mídia e em espaços de lazer.

Os acidentes de trânsito e homicídios estão entre as principais causas de morbimortalidade no Brasil e trazem altos custos para os cofres públicos e repercussões 
importantes na qualidade de vida dos sujeitos (SOUZA JUNIOR et al., 2003; VIEIRA; VIEIRA; ZIMMERMANN, 2003; FERNANDES NETO et al., 2003; SILVA; CAUÁS, 2004; JORGE, 2004; GAWRYSZEWSKI; KOIZUMI; MELLO-JORGE, 2004; SILVA; PANHOCA, 2005; PATROCÍNIO et al., 2005; GUIMARÃES et al., 2005; CARDONA et al., 2005; MARTINI et al., 2006; MACEDO et al., 2007; MESQUITA FILHO; MELLO-JORGE, 2007; GAWRYSZESKI, 2007; SÁ; WERLANG, 2007). É importante pontuar que os acidentes de trânsito não são considerados como violência no Relatório Mundial, em virtude da não intencionalidade destas ocasiōes. No entanto, no Brasil, têm sido preconizadas ações de redução de acidentes de trânsito de forma concomitante a ações direcionadas para diminuição da violência, conforme se constata na Política Nacional de Redução de Acidentes e Violência. A efetividade destas ações vem sendo comprovada por resultados positivos de ações para o combate à violência que está ocorrendo em todo o país, a partir da crença de uma formação para a cultura de paz e não-violência (ALVES SOBRINHO; INOJOSA, 2005; BATISTA, 2006; ROSA; MALTA; LOPES, 2007; VIANNA; OLIVEIRA; ESPÍRITO-SANTO, 2007; DANTAS, 2007).

A análise dos resumos que compuseram este estudo não permitiu a identificação de estudos que enfocassem diretamente a discussão da violência que permeia o cotidiano dos grandes centros urbanos vinculada ao tráfico de drogas, o que aponta a necessidade de maior apropriação da saúde sobre o tema. Os homicídios, que muitas vezes estão associados a estas situações, se caracterizam como umas das principais causa de morte em homens jovens, e os dados decorrentes das morbidades relacionadas a situações de violência no mundo do tráfico são inexistentes.

Nos estudos que abordaram a violência no mundo do trabalho, também se observa um recorte de gênero neste contexto. A violência praticada e/ou sofrida pela mulher em seu ambiente de trabalho está associada ao uso de drogas lícitas e ilícitas, sendo que muitas estas sofrem, além da violência física, o assédio sexual (MUSAYÓN; CAUFIELD, 2005; DAVID; CAUFIELD, 2005; ALONSO CASTILLO et al., 2006). De uma forma geral, os profissionais de saúde são vítimas de violência no trabalho, sobretudo por agressão verbal, seguida de assédio moral e sexual (CEZAR; MARZIALE, 2006), sendo que quando se analisa especificamente a classe médica, a principal tipologia identificada da violência é a emocional (SCHRODER et al., 2007). Os resultados em relação aos profissionais 
de enfermagem apontam os mesmos como receptores e/ou agentes da violência no trabalho (DIAS; RAMOS, 2003; LEAL; LOPES, 2005; COSTA; MARZIALE, 2006; CEZAR; MARZIALE, 2006; SOUZA; SANTANA, 2007). Além dos profissionais de saúde, outros profissionais são identificados como vulneráveis a violência no trabalho como trabalhadores braçais, policiais e principalmente motoristas (SOUZA; MINAYO, 2005; ANCHIETA; GALINKIN, 2005; ROBAZZI, et al., 2006; SOUZA; PORTINHO; BARREIROS, 2006).

Segundo Krug et al.(2002), a violência no trabalho abrange, além do comportamento físico, o psicológico, como comportamentos prepotentes agressivos, assédio sexual, ameaças, intimidações, entre outras. Esta violência no trabalho ocasiona uma ruptura imediata, ou em longo prazo, dos relacionamentos interpessoais, assim como uma desestruturação no ambiente de trabalho, gerando custos diretos (em decorrência de enfermidades, absenteísmo, invalidez, morte e rotatividade de funcionários) e indiretos (menor produtividade, menor qualidade de produtos e serviços). A violência no trabalho se configura como problema estrutural com causas socioeconômicas, culturais e organizacionais, sendo que, para evitá-la, é necessária uma abordagem mais abrangente que ofereça meios para uma ação imediata e sustentável.

Outra situação discutida nesta categoria é a violência no contexto familiar de uma forma geral, sem discussōes específicas sobre as vítimas deste contexto (essas discussões foram realizadas nas categorias relacionadas a gênero, infância e adolescência e velhice). Em geral, os autores discutem a violência no ambiente doméstico como relacionada ao conflito entre as concepções hegemônicas vinculadas aos papéis de gênero e novas configurações da sociedade em geral (RABELO; MELO; CAMPOS, 2006; DINIZ; SANTOS; LOPES, 2007; SANTOS; COSTA, 2004).

Conforme discutido anteriormente, a violência contra as mulheres e as crianças e adolescentes, principais vítimas da violência no contexto doméstico e que têm nos homens seu principal perpetuador, relaciona-se muitas vezes a tentativas de manutenção de situações de opressão, naturalizadas e banalizadas em nossa sociedade, sustentadas por visões que afirmam a inferioridade feminina, o adultocentrismo e o patriarcardo. Segundo Silva, Coelho e Caponi (2007), neste contexto se destaca a violência psicológica que, apesar de sua presença muitas vezes cotidiana, não tem sido adequadamente abordada, uma vez as atitudes 
não são muitas vezes relacionadas ao conceito de violência, caracterizando uma situação de invisibilidade do problema.

É importante que os profissionais de saúde reflitam sobre suas práticas, assim como criem e consolidem espaços de discussão sobre a caracterização e manifestação das relações de gênero e autoridade no âmbito familiar, como forma de promoção de saúde tanto das mulheres, crianças, adolescentes, como dos próprios homens. Especificamente em relação aos homens considera-se que a valorização cultural do homem forte e dominador muitas vezes os coloca em situação de vulnerabilidade, fazendo-os se expor a situações de risco no papel de agressor, ao buscarem a afirmação deste status social na relação de dominação, comprometendo sua saúde e a dos que estão ao seu redor (NASCIMENTO; GOMES; REBELLO, 2009).

Nesta categoria também foram alocados os estudos que abordam a violência em contextos institucionais, sendo que estes discutem principalmente aspectos relacionados à ocorrência da violência em instituiçôes educacionais (SEQUEIRA, 2004; LIBERAL, 2005). Esses autores apontam que tanto a escola como a família possuem papéis importantes no campo da prevenção de violência. Os estudos de Anser, Joly e Vendramini (2003); Loureiro e Queiroz (2005) e de Souza e Ristum (2005) apontaram que os alunos são os principais agentes da violência contra os professores, sendo esta física, verbal e moral. Os professores consideram como causas desta violência uma desestruturação familiar e o ambiente em que o aluno ou a escola estão inseridos (LOUREIRO; DE QUEIROZ, 2005). Não foram encontrados no período estudo, pesquisas que buscassem caracterizar a violência praticada por professores contra seus alunos.

Somente um dos artigos tem como foco principal a violência em instituições sócioeducativas, e apontou que mudanças devem ser realizadas nas representações arcaicas vinculadas à instituição (LIMA et al., 2006). É importante pontuarmos o silêncio acadêmico da área da saúde em torno da violência em instituições sócioeducativas, que é alardeada frequentemente nos diferentes meios de comunicação.

Outro aspecto discutido nesta categoria se refere à abordagem da violência pelos meios de comunicação, sendo que os autores discutem a contribuição da mídia para a mitificação do fenômeno da violência, colocando-a como um problema individual (RAMOS; NOVO, 2003; MISSE, 2007). Os artigos de Batista, Fukahori e Haydu (2004) e de Coelho Junior (2005) têm como foco, 
respectivamente, a influência dos meios de comunicação no comportamento violento de garotas e garotos e a violência estilizada sob a forma de imagens. De acordo com Krug et al. (2002), há mais de 40 anos os pesquisadores analisam o impacto da mídia sobre o comportamento violento, sendo constatado o aumento do comportamento agressivo em relação a amigos, colegas e estranhos, de crianças e adolescentes expostos à violência exibida pela mídia (KRUG et al., 2002).

Finalmente, nesta categoria, alguns autores discutem a violência no contexto do futebol, sobrtudo no que se relaciona a violência entre as torcidas e entre os jogadores (REIS, 2003; BARROSO; VELHO; FENSTERSEIFER, 2005; BARROSO et al., 2007). Consta-se nestas pesquisas que a violência neste contexto está relacionada tanto a fatores sociais e econômicos, mas também à valorização da individualidade e o prazer e excitação gerados pela violência principalmente na juventude (PIMENTA, 2000).

\section{Considerações finais}

É notório, no âmbito nacional e internacional, que a violência é tida como uma questão social e de saúde pública, visto que está relacionada com a violação de direitos, diminuição da qualidade de vida e limitações existenciais com variadas expressões nos diversos contextos. A violência pode ser identificada nos espaços públicos e privados, nas instituições, nas relações grupais e/ou interpessoais, em períodos de guerra ou de suposta paz. Apesar de ainda não existirem elementos suficientes para lidar com a totalidade da complexidade do fenômeno, tem-se observado o aumento da sensibilização por parte da população e a concomitante preocupação da comunidade científica em compreender e justificar este "novo" problema de saúde pública.

A análise realizada neste estudo suscita algumas reflexões que são importantes para o direcionamento de novas pesquisas sobre as relações entre violência e saúde. Inicialmente, é importante destacar que em todas as categorias analisadas os pesquisadores chamam a atenção para a interação de aspectos biológicos, culturais, sociais, econômicos e políticos na gênese da violência. Esta interação de fatores, que caracteriza a complexidade do fenômeno, traz em si a necessidade de uma maior articulação de diferentes setores sociais, entre eles saúde educação, assistência social e segurança pública, no planejamento, sistematização e avaliação de ações de prevenção e enfrentamento da violência. 
Além disso, foi possível constatar que alguns temas, apesar de relevantes socialmente, tiveram pouca expressão na produção científica do período estudado, como a violência cometida com grupos particularmente vulneráveis como idosos e homossexuais, aquela que acontece em espaços sócio-educativos e a relacionada ao tráfico de drogas. Nesta mesma direção, observa-se a ausência de estudos direcionados para a violência sofrida por pessoas com deficiências e por indígenas. Estas lacunas na produção do conhecimento indicam a necessidade de maior apropriação da temática pelo setor saúde no que se refere a sua caracterização e impacto na percepção de qualidade de vida dos sujeitos que vivenciam o fenômeno.

De uma forma geral, a grande maioria dos estudos se destina a caracterizar a violência e dão indícios sobre possíveis estratégias de enfrentamento. No entanto, são poucos os estudos que se referem especificamente à descrição e análise da efetividade dessas estratégias. Neste sentido, é importante que não só os pesquisadores inseridos no âmbito acadêmico, mas também os profissionais de saúde que enfrentam a violência e suas consequências cotidianamente direcionem esforços para uma maior sistematização no sentido da produção de conhecimento sobre suas ações, de forma que essas experiências possam ser compartilhadas em diferentes contextos, avaliadas quantitativa e qualitativamente e posteriormente subsidiarem a elaboração de diretrizes efetivas mais amplas de intervenções.

Destaca-se neste estudo a limitada quantidade de estudos que se direcionam para a caracterização e compreensão do fenômeno a partir da perspectiva do agressor. Esta abordagem merece maior atenção por parte dos pesquisadores, considerando-se que a violência, conforme preconiza seu conceito proveniente da OMS, explícito em Krug et al. (2002), se refere às relaçôes de poder constituídas, e que a transformação efetiva destas implica intervençôes direcionadas aos dois polos, tanto vítimas como agressores.

A partir da análise realizada neste trabalho, salientamos a necessidade de uma maior atenção dos autores e editores dos periódicos para a quantidade e qualidade das informaçóes contidas no resumo, uma vez que em um grande número de estudos não foi possível identificar informações essenciais (como objetivo, metodologia e resultados) para a decisão pela leitura ou não do trabalho completo. Finalmente, é importante pontuarmos que este estudo não abrangeu toda a produção nacional da área da saúde, uma vez que muitos pesquisadores 
brasileiros publicam em periódicos internacionais, muitos periódicos não estão cadastrados na base de dados utilizada, ou os estudos foram excluídos por não apresentarem resumo. No entanto, acredita-se que a partir do grande número de resumos analisados, foi possível construir um mapeamento da temática produzida sobre violência e saúde que pode contribuir para a identificação de novas demandas para a pesquisa, bem como para o acesso mais ágil dos profissionais ao conhecimento produzido no período do estudo.

\section{Referências}

BARDIN, L. Análise de conteúdo. Lisboa: Edições 70, 1979.

GOMES, R. Sexualidade masculina, gênero e saúde. Rio de Janeiro, Fiocruz, 2008, 183p

GOMES, R.; NASCIMENTO, E.F. do. A produção do conhecimento da saúde pública sobre a relação homem-saúde: uma revisão bibliográfica. Cad. Saúde Pública, Rio de Janeiro, v. 22 , n. $5,2006$.

PIMENTA, C.A.M. Violência contra torcidas organizadas de futebol. São Paulo em Perspectiva, São Paulo, v. 14, n. 2, p. 122-129, 2000

LOURO, G.L. Gênero, sexualidade e educação: uma perspectiva pós-estruturalista. $3^{a}$ ed. Petrópolis: Vozes, 1999. 111p.

MINAYO, M. C. S. Violência e saúde. Rio de Janeiro: Fiocruz, 2006, 132p.

NASCIMENTO, E.F.; GOMES, R.; REBELLO, L.E.F.S. Violência é coisa de homem? A naturalização da violência nas falas de homens jovens. Ciência e Saúde Coletiva. V. 14, n. 4, 2009, p. 1151-1157

SCHRAIBER, L.B. et al. Violência de Gênero no campo da Saúde Coletiva: conquistas e desafios. Ciência e Saúde Coletiva, v. 14, n. 4, p. 1019-1027, 2009. 


\begin{tabular}{|c|c|c|c|c|}
\hline Ano & Autores & Título do artigo & Periódico & Vol. (n) \\
\hline 2003 & Azevedo & Concepções sobre criminalidade e modelos de policiamento & Psicol. Cienc. Prof & $23(3)$ \\
\hline 2003 & Souza & $\begin{array}{l}\text { É possível uma psicologia para a paz? Apresentando a Peace } \\
\text { Psychology }\end{array}$ & Psico (Porto Alegre) & $34(1)$ \\
\hline 2003 & Lowenkron & Psicanálise, violência individual, violência social & Rev. Bras. Psicanal. & $37(2 / 3)$ \\
\hline 2003 & Fagundes & A psicanálise diante da violência & Rev. Bras. Psicanal & $37(2 / 3)$ \\
\hline 2003 & Bastos & Armagedon: a violência no mundo contemporâneo & Rev. Bras. Psicanal & $37(2 / 3)$ \\
\hline 2003 & Reichenhei, Moraes & $\begin{array}{l}\text { Adaptação transcultural do instrumento Parent-Child Conflict } \\
\text { Tactics Scales (CTSPC) utilizado para identificar a violência } \\
\text { contra a criança }\end{array}$ & Cad. Saúde Pública & $19(6)$ \\
\hline 2003 & $\begin{array}{l}\text { Oliveira, } \\
\text { Dalgalarrondo }\end{array}$ & $\begin{array}{l}\text { Os determinantes sociais na etiologia das lesöes traumáticas do } \\
\text { sistema nervoso central }\end{array}$ & Fisioter. Mov & $16(2)$ \\
\hline 2003 & $\begin{array}{l}\text { Hasselman, } \\
\text { Reichenhei }\end{array}$ & $\begin{array}{l}\text { Adaptação transcultural da versão em português da Conflict } \\
\text { Tactics Scales Form R (CTS-1), usada para aferir violência no } \\
\text { casal: equivalências semântica e de mensuração }\end{array}$ & Cad. Saúde Pública & $19(4)$ \\
\hline 2004 & Fortes & $\begin{array}{l}\text { As condiçốes de vida, de trabalho e de saúde como caldo de } \\
\text { cultura para a violência }\end{array}$ & Bioética & $12(2)$ \\
\hline 2004 & Girola & Violência e saúde: uma perspectiva psicanalítica & Bioética & $12(2)$ \\
\hline 2004 & Braz & Bioética e violência & Bioética & $12(2)$ \\
\hline 2004 & Anjos & Violência e religiōes: uma introdução & Bioética & $12(2)$ \\
\hline 2004 & Gomes & Saúde e violência, uma contradição bioética & Bioética & $12(2)$ \\
\hline 2004 & Gerado & $\begin{array}{l}\text { Psicologia jurídica: uma possibilidade de discussão sobre a } \\
\text { violência }\end{array}$ & Psicol. Rev; & $13(1)$ \\
\hline 2004 & Santi & Concepçôes sobre criminalidade e modelos de policiamento & Psyche (São Paulo) & $23(3)$ \\
\hline 2004 & Abdalla-Filho & Avaliação de risco de violência em Psiquiatria Forense & $\begin{array}{l}\text { Rev. Psiquiatr. Clin. (São } \\
\text { Paulo); }\end{array}$ & $31(6)$ \\
\hline 2004 & Meloni, Laranjeira & Custo social e de saúde do consumo do álcool & Rev. Bras. Psiquiatr & $26($ supl $)$ \\
\hline 2004 & Fandino Marino & Ciclos históricos da violência na América Latina & São Paulo Perspect. & $18(1)$ \\
\hline 2004 & $\begin{array}{l}\text { Peixoto, Lima, } \\
\text { Durante }\end{array}$ & Metodologias e criminalidade violenta no Brasil & São Paulo Perspect.; & $18(1)$ \\
\hline 2004 & Lessa & $\begin{array}{l}\text { Arqueologia da agressividade humana: a violência sob uma } \\
\text { perspectiva paleoepidemiológica }\end{array}$ & $\begin{array}{l}\text { Hist. Cienc. Saude- } \\
\text { Manguinhos }\end{array}$ & $11(2)$ \\
\hline 2004 & Pesce et al. & $\begin{array}{l}\text { Risco e proteção: em busca de um equilíbrio promotor de } \\
\text { resiliência }\end{array}$ & Psicol. Teor. Pesqui; & $20(2)$ \\
\hline 2005 & Rosato & A psicologia no Provita: trajetórias da subjetividade e cidadania & Psicol. Cienc. Prof. & $24(4)$ \\
\hline 2005 & Oliveira & Reflexões sobre agressão e violência: da biologia à cultura & Junguiana & SV (23) \\
\hline 2005 & Marinho & Barbárie? Civilização: um ponto de vista psicanalítico & Rev. Bras. Psicana & $39(3)$ \\
\hline 2005 & Cassorla & Barbárie, terrorismo e paranóia & Rev. Bras. Psicanal & $39(3)$ \\
\hline
\end{tabular}




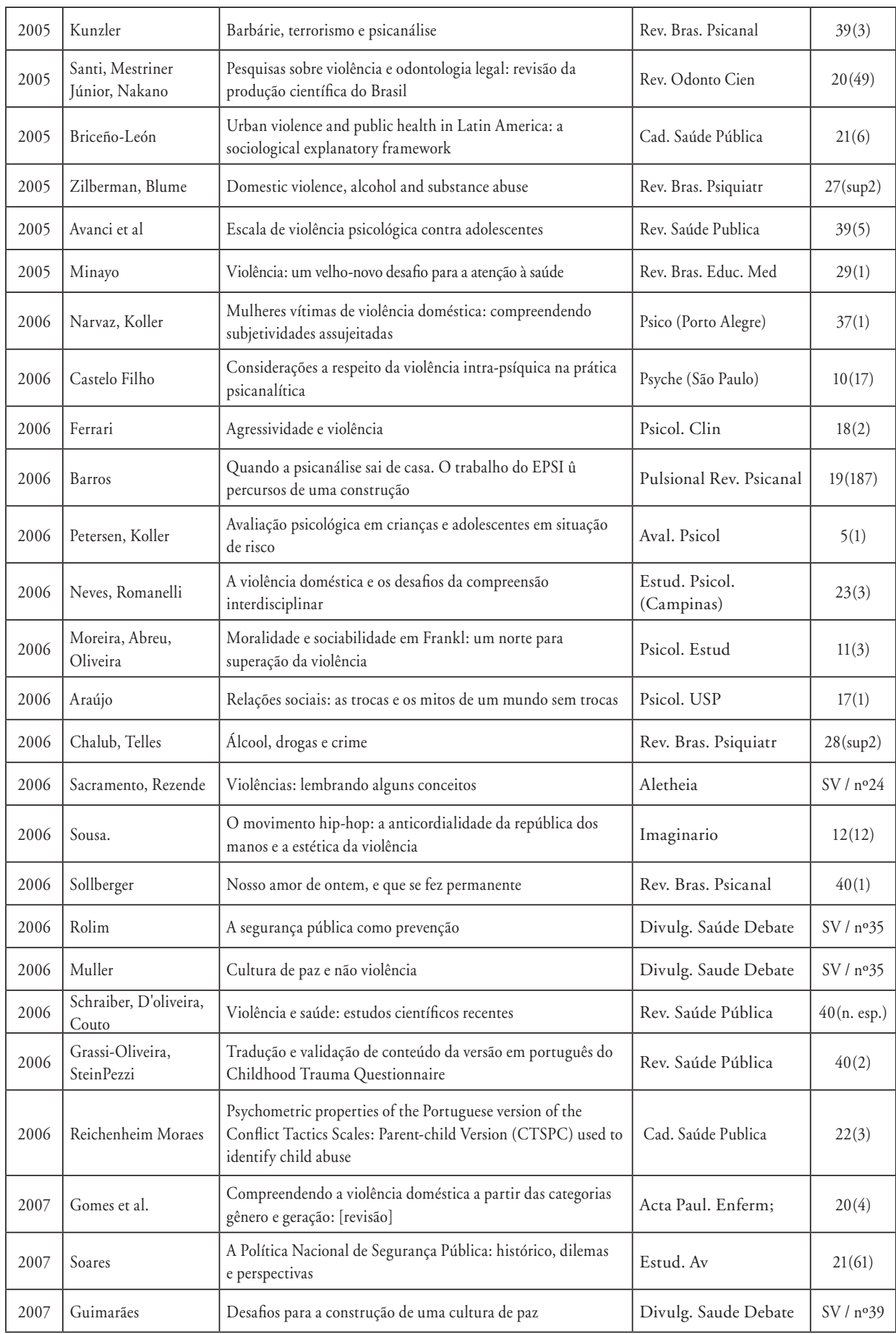




\begin{tabular}{|l|l|l|l|c|}
\hline 2007 & Silva et al. & $\begin{array}{l}\text { Agenda de prioridades da vigilância e prevenção de acidentes } \\
\text { e violências aprovada no I Seminário Nacional de Doenças e } \\
\text { Agravos não Transmissíveis e Promoção da Saúde }\end{array}$ & Epidemiol. Serv. Saude & 16(1) \\
\hline 2007 & Malta et al. & $\begin{array}{l}\text { Iniciativas de vigilância e prevenção de acidentes e violências no } \\
\text { contexto do Sistema Unico de Saúde (SUS) }\end{array}$ & Epidemiol. Serv. Saude & 16(1) \\
\hline 2007 & Ruiz et al. & $\begin{array}{l}\text { Psiconeuroendocrinologia do transtorno de estresse pós- } \\
\text { traumático }\end{array}$ & Rev. Bras. Psiquiatr; & 29(supl.1) \\
\hline 2007 & Saliba et al & $\begin{array}{l}\text { Responsabilidade do profissional de saúde sobre a notificação } \\
\text { de casos de violência doméstica }\end{array}$ & Rev. Saúde Pública & $41(3)$ \\
\hline ReichenheimKlein, & $\begin{array}{l}\text { Assessing the physical violence component of the Revised } \\
\text { Conflict Tactics Scales when used in heterosexual couples: an } \\
\text { item response theory analysis }\end{array}$ & Cad. Saúde Pública & $23(1)$ \\
\hline
\end{tabular}

Quadro II- Resumos incluídos na categoria Violência contra idosos

\begin{tabular}{|c|c|c|c|c|}
\hline Ano & Autores & Título do artigo & Periódico & Vol. (n) \\
\hline 2003 & Fonseca, Gonsalves & Violência contra o idoso: suportes legais para a intervenção. & $\begin{array}{l}\text { Rev Interação Em } \\
\text { Psicologia }\end{array}$ & $7(2)$ \\
\hline 2004 & Chaves, Costa & $\begin{array}{l}\text { O idoso como vítima na cidade de Belo Horizonte: as denúncias } \\
\text { na delegacia especializada de proteção ao idoso - Depi/MG. }\end{array}$ & Rev. Kairós & $41(2)$ \\
\hline 2007 & Santos et al. & A construção da violência contra idosos. & $\begin{array}{l}\text { Rev Bras. Geriatria E } \\
\text { Gerontologia }\end{array}$ & $10(1)$ \\
\hline 2007 & Espíndola & $\begin{array}{l}\text { Prevalência de maus-tratos na terceira idade: revisão } \\
\text { sistemática. }\end{array}$ & Rev Saúde Pública & $7(2)$ \\
\hline
\end{tabular}

\section{Quadro III - Resumos incluídos na categoria Violência e Gênero}

\begin{tabular}{|c|c|c|c|c|}
\hline Ano & Autores & Título do artigo & Periódico & Vol. (n) \\
\hline 2003 & Mattar, Carreteiro & $\begin{array}{l}\text { Percurso biográfico, percurso social: violência conjugal em } \\
\text { análise }\end{array}$ & Psicol. Clin & $15(2)$ \\
\hline 2003 & Oliveira et al & $\begin{array}{l}\text { Perfil e sofrimento de mulheres vítimas de violência atendidas } \\
\text { em uma delegacia especializada }\end{array}$ & Rev. RENE & $4(2)$ \\
\hline 2003 & Carrasco & Violência conjugal: um estudo de caso & Aletheia & $(17 / 18)$ \\
\hline 2003 & Blay & Violência contra a mulher e as negociaçôes & Estud. Av. & $17(49)$ \\
\hline 2003 & $\begin{array}{l}\text { Shimazaki, Lopes, } \\
\text { Oliveira }\end{array}$ & Saúde sim violência não: programa mulher de verdade & Divulg. Saúde Debate & $\mathrm{SN} /(26)$ \\
\hline 2003 & Soares & $\begin{array}{l}\text { Profissionais de saúde frente ao aborto legal no Brasil: desafios, } \\
\text { conflitos e significados }\end{array}$ & Cad. Saúde Pública & 19 (supl.2) \\
\hline 2003 & Silva & $\begin{array}{l}\text { Violência contra mulheres: a experiência de usuárias de um } \\
\text { serviço de urgência e emergência de Salvador, Bahia, Brasil }\end{array}$ & Cad. Saúde Pública & 19 (supl.2) \\
\hline 2003 & Porto et al. & $\begin{array}{l}\text { A saúde da mulher em situação de violência: representações e } \\
\text { decisōes de gestores/as municipais do Sistema Único de Saúde }\end{array}$ & Cad. Saúde Pública & $19($ supl.2) \\
\hline 2003 & Cavalcanti & Violência contra a mulher: um problema de saúde & Rev. Ginecol. Obstet. & $14(4)$ \\
\hline 2003 & Day et al. & Violência doméstica e suas diferentes manifestaçōes & $\begin{array}{l}\text { Rev. Psiquiatr. Rio } \\
\text { Gd. Sul }\end{array}$ & 25(supl.1) \\
\hline
\end{tabular}




\begin{tabular}{|c|c|c|c|c|}
\hline 2003 & Rotania et al. & Violência contra a mulher: o perigo mora da porta para dentro & $\begin{array}{l}\text { Esc. Anna Nery Rev. } \\
\text { Enferm. }\end{array}$ & $7(1)$ \\
\hline 2003 & Menezes et al . & $\begin{array}{l}\text { Violência física doméstica e gestação: resultados de um } \\
\text { inquérito no puerpério }\end{array}$ & $\begin{array}{l}\text { Rev. Bras. Ginecol. } \\
\text { Obstet. }\end{array}$ & $25(5)$ \\
\hline 2003 & Meneghel et al. & $\begin{array}{l}\text { Impacto de grupos de mulheres em situação de vulnerabilidade } \\
\text { de gênero }\end{array}$ & Cad. Saúde Pública & $19(4)$ \\
\hline 2003 & Schraiber et al. & Violência vivida: a dor que não tem nome & $\begin{array}{l}\text { Interface Comun. Saúde } \\
\text { Educ. }\end{array}$ & $7(12)$ \\
\hline 2003 & Castro, Riquer & $\begin{array}{l}\text { La investigación sobre violencia contra las mujeres en América } \\
\text { Latina: entre el empirismo ciego y la teoría sin datos }\end{array}$ & Cad. Saúde Pública & 19(1) \\
\hline 2004 & Porto, Luz & Matizes da violência contra a mulher: conhecendo o fenômeno & Rev. Gauch. Enferm; & $25(2)$ \\
\hline 2004 & Pereira & $\begin{array}{l}\text { Poder, violência e dominação simbólicas nos serviços públicos } \\
\text { de saúde }\end{array}$ & $\begin{array}{l}\text { Texto \& Contexto } \\
\text { Enferm. }\end{array}$ & $13(3)$ \\
\hline 2004 & Squinca,Diniz, Braga & $\begin{array}{l}\text { Violência sexual contra a mulher: um desafio para o ensino e a } \\
\text { pesquisa no Brasil }\end{array}$ & Bioética & $12(2)$ \\
\hline 2004 & Pacheco et al & $\begin{array}{l}\text { Atendimento integrado às vítimas de crime sexual: programa } \\
\text { bem-me-quer }\end{array}$ & Femina & $32(6)$ \\
\hline 2004 & $\begin{array}{l}\text { Faúndes, Araújo, } \\
\text { Anadalaft Neto }\end{array}$ & $\begin{array}{l}\text { Relatório final: VIII Fórum Interprofissional para } \\
\text { Atendimento Integral da Mulher Vítima de Violência Sexual }\end{array}$ & Femina & $32(6)$ \\
\hline 2004 & Nunan & $\begin{array}{l}\text { Violência doméstica entre casais homossexuais: o segundo } \\
\text { armário? }\end{array}$ & Psico (Porto Alegre) & $35(1)$ \\
\hline 2004 & Galvāo, Andrade & $\begin{array}{l}\text { Violência contra a mulher: análise de casos atendidos em } \\
\text { serviço de atençăo à mulher em município do sul do Brasil. }\end{array}$ & Saúde Soc. & $13(2)$ \\
\hline 2004 & Aldrighi & $\begin{array}{l}\text { Prevalência e cronicidade da violência física no namoro entre } \\
\text { jovens universitários do estado de São Paulo - Brasil }\end{array}$ & Psicol. Teor. Prat. & $6(1)$ \\
\hline 2004 & Machado & Narrativa de mulheres vítimas de violência: passos do processo & Psicol. Teor. Prat. & $6(1)$ \\
\hline 2004 & $\begin{array}{l}\text { Araujo, Progianti, } \\
\text { Vargens }\end{array}$ & $\begin{array}{l}\text { A consulta de enfermagem ginecológica e a redução da } \\
\text { violência de gênero }\end{array}$ & Rev. Enferm. UERJ & $12(3)$ \\
\hline 2004 & Penna, Santos, Souza & $\begin{array}{l}\text { A produção científica sobre violência doméstica na área da } \\
\text { saúde pública }\end{array}$ & Rev. Enferm. UERJ & $12(2)$ \\
\hline 2004 & Vaiz Bonifaz, Nakano & $\begin{array}{l}\text { La violencia intrafamiliar, el uso de drogas en la pareja, desde } \\
\text { la perspectiva de la mujer maltratada }\end{array}$ & $\begin{array}{l}\text { Rev. Latinoam. } \\
\text { Enferm; }\end{array}$ & 12(n. esp) \\
\hline 2004 & Lopes et al. & $\begin{array}{l}\text { Caracterização da violência sexual em mulheres atendidas no } \\
\text { projeto Maria-Maria em Teresina-PI }\end{array}$ & $\begin{array}{l}\text { Rev. Bras. Ginecol. } \\
\text { Obstet. }\end{array}$ & $26(2)$ \\
\hline 2004 & Castro, Ruíz & $\begin{array}{l}\text { Prevalencia y severidad de la violencia contra mujeres } \\
\text { embarazadas, México }\end{array}$ & Rev. Saúde Pública & $38(1)$ \\
\hline 2004 & Reis, Martin, Ferriani & $\begin{array}{l}\text { Mulheres vítimas de violência sexual: meios coercitivos e } \\
\text { produçấo de lesões năo-genitais }\end{array}$ & Cad. Saúde Pública & $20(2)$ \\
\hline 2005 & Alvim, Souza & $\begin{array}{l}\text { Violência conjugal em uma perspectiva relacional: homens e } \\
\text { mulheres agredidos/agressores }\end{array}$ & Psicol. Teor. Prat. & $7(2)$ \\
\hline 2005 & Coelho & $\begin{array}{l}\text { A participação de psicólogos na avaliação de políticas públicas } \\
\text { para mulheres }\end{array}$ & Psicol. Argum. & $23(40)$ \\
\hline 2005 & Gomes & $\begin{array}{l}\text { Transmissão psíquica transgeracional e violência conjugal: um } \\
\text { relato de caso }\end{array}$ & Bol. Psicol & $55(123)$ \\
\hline 2005 & Gomes, Freire & $\begin{array}{l}\text { Vivência de violência familiar: homens que violentam suas } \\
\text { companheiras }\end{array}$ & Rev. Bras. Enferm. & $58(2)$ \\
\hline
\end{tabular}




\begin{tabular}{|c|c|c|c|c|}
\hline 2005 & Alves, Diniz & $\begin{array}{l}\text { Eu digo não, ela diz sim: a violência conjugal no discurso } \\
\text { masculino }\end{array}$ & Rev. Bras. Enferm. & $58(4)$ \\
\hline 2005 & $\begin{array}{l}\text { Ramão, Meneghel, } \\
\text { Oliveira }\end{array}$ & $\begin{array}{l}\text { Nos caminhos de Iansãa: cartografando a subjetividade de } \\
\text { mulheres em situação de violência de gênero }\end{array}$ & Psicol. Soc. & $17(2)$ \\
\hline 2005 & $\begin{array}{l}\text { Roldán, Galera, } \\
\text { O'brien }\end{array}$ & $\begin{array}{l}\text { Perception of the mothering role of women who live in a } \\
\text { context of drugs and violence }\end{array}$ & Rev. Latinoam. Enferm. & $\begin{array}{c}13(2, \mathrm{n} \\
\mathrm{esp})\end{array}$ \\
\hline 2005 & $\begin{array}{l}\text { Cortez, Padovani, } \\
\text { Williams }\end{array}$ & $\begin{array}{l}\text { Terapia de grupo cognitivo-comportamental com agressores } \\
\text { conjugais }\end{array}$ & $\begin{array}{l}\text { Estud. Psicol. } \\
\text { (Campinas) }\end{array}$ & $22(1)$ \\
\hline 2005 & Fraga et al & Trauma abdominal em grávidas & $\begin{array}{l}\text { Rev. Bras. Ginecol. } \\
\text { Obstet. }\end{array}$ & $27(9)$ \\
\hline 2005 & Pedreira et al. & Violência doméstica e saúde da mulher & Rev. Med. (São Paulo) & $84(2)$ \\
\hline 2005 & Kronbauer, Meneghel & Perfil da violência de gênero perpetrada por companheiro & Rev. Saúde Pública & $39(5)$ \\
\hline 2005 & Campos et al. & $\begin{array}{l}\text { Violência sexual: integração saúde e segurança pública no } \\
\text { atendimento imediato à vítima }\end{array}$ & Saúde Soc. & $14(1)$ \\
\hline 2005 & Oliveira et al. & $\begin{array}{l}\text { Atendimento às mulheres vítimas de violência sexual: um } \\
\text { estudo qualitativo }\end{array}$ & Rev. Saúde Publica & $39(3)$ \\
\hline 2005 & Meneghel, et al. & $\begin{array}{l}\text { Cotidiano ritualizado: grupos de mulheres no enfrentamento à } \\
\text { violência de gênero }\end{array}$ & Cienc. Saúde Coletiva & $10(1)$ \\
\hline 2005 & $\begin{array}{l}\text { Oshikata, Bedone, } \\
\text { Faúndes. }\end{array}$ & $\begin{array}{l}\text { Atendimento de emergência a mulheres que sofreram violência } \\
\text { sexual: características das mulheres e resultados até seis meses } \\
\text { pós-agressão }\end{array}$ & Cad. Saúde Pública & $21(1)$ \\
\hline 2005 & Adeodato et al & $\begin{array}{l}\text { Qualidade de vida e depressão em mulheres vítimas de seus } \\
\text { parceiros }\end{array}$ & Rev. Saúde Publica & $39(1)$ \\
\hline 2005 & Dantas-Berger, Giffin & $\begin{array}{l}\text { A violência nas relacôes de conjugalidade: invisibilidade e } \\
\text { banalizacão da violência sexual? }\end{array}$ & Cad. Saúde Pública & $21(2)$ \\
\hline 2006 & Quayle & $\begin{array}{l}\text { Violência de gênero e saúde reprodutiva: subsídios para o } \\
\text { psicólogo hospitalar }\end{array}$ & Mudanças & $14(1)$ \\
\hline 2006 & Oliveira, Carvalho & $\begin{array}{l}\text { Perfil das mulheres atendidas no Programa Municipal de } \\
\text { Atendimento àMulher Vítima de Violência Sexual em Londrina- } \\
\text { PR e as circunstânciasda violência sexual sofrida: período de } \\
\text { outubro de } 2001 \text { a agosto de } 2004\end{array}$ & $\begin{array}{l}\text { Semina Cienc. Biol. } \\
\text { Saúde }\end{array}$ & $27(1)$ \\
\hline 2006 & Guareschi et al & Discussōes sobre violência: trabalhando a produção de sentidos & Psicol. Reflex. Crit. & $1(19)$ \\
\hline 2006 & $\begin{array}{l}\text { Rabello, Caldas } \\
\text { Júnior }\end{array}$ & Violência Contra a Mulher em João Pessoa - Paraíba - Brasil & $\begin{array}{l}\text { Rev. Bras. Cienc. } \\
\text { Saúde }\end{array}$ & $10(1)$ \\
\hline 2006 & Carrara, Vianna & $\begin{array}{l}\text { "Tá lá o corpo estendido no chão... ": a violência letal contra } \\
\text { travestis no município do Rio de Janeiro }\end{array}$ & Physis (Rio J.) & $16(2)$ \\
\hline 2006 & Brandão & $\begin{array}{l}\text { Renunciantes de direitos? A problemática do enfrentamento } \\
\text { público da violência contra a mulher: o caso da delegacia da } \\
\text { mulher }\end{array}$ & Physis (Rio J.) & $16(2)$ \\
\hline 2006 & Ramos, Carrara & $\begin{array}{l}\text { A constituição da problemática da violência contra } \\
\text { homossexuais: a articulaçâao entre ativismo e academia na } \\
\text { elaboração de políticas públicas }\end{array}$ & Physis (Rio J.) & $16(2)$ \\
\hline 2006 & Sarti, Barbosa, Suarez & Violência e gênero: vítimas demarcadas & Physis (Rio J.) & $16(2)$ \\
\hline 2006 & $\begin{array}{l}\text { Casique, } \\
\text { Furegato }\end{array}$ & Violence against women: theoretical reflections & $\begin{array}{l}\text { Rev. Latinoam. } \\
\text { Enferm }\end{array}$ & $14(6)$ \\
\hline
\end{tabular}




\begin{tabular}{|c|c|c|c|c|}
\hline 2006 & $\begin{array}{l}\text { Marinheir } \\
\text { Vieira, Souza }\end{array}$ & $\begin{array}{l}\text { Prevalência da violência contra a mulher usuária de serviço } \\
\text { de saúde }\end{array}$ & Rev. Saúde Pública & $40(4)$ \\
\hline 2006 & $\begin{array}{l}\text { Vianna, Bomfim, } \\
\text { Chicone }\end{array}$ & Auto-estima de mulheres que sofreram violência & $\begin{array}{l}\text { Rev. Latinoam. } \\
\text { Enferm }\end{array}$ & $14(5)$ \\
\hline 2006 & Garbin et al & Violência doméstica: análise das lesōes em mulheres & Cad. Saúde Pública & $22(12)$ \\
\hline 2006 & Motta & $\begin{array}{l}\text { Raça, gênero, classe e estrupo: exclusōes e violências nas } \\
\text { relaçóes entre nativos e turistas em Florianópolis }\end{array}$ & Physis (Rio J.) & $16(1)$ \\
\hline 2006 & Herrera, Agoff & $\begin{array}{l}\text { Dilemas do profissional de saúde acerca da violência doméstica } \\
\text { no México }\end{array}$ & Cad. Saúde Pública & $22(11)$ \\
\hline 2006 & $\begin{array}{l}\text { Andrade } \\
\text { Viana, Silveira }\end{array}$ & Epidemiologia dos transtornos psiquiátricos na mulher & $\begin{array}{l}\text { Rev. Psiquiatr. Clin. } \\
\text { (São Paulo) }\end{array}$ & $33(2)$ \\
\hline 2006 & Narvaz, Koller & $\begin{array}{l}\text { Famílias e patriarcado: da prescrição normativa à subversão } \\
\text { criativa }\end{array}$ & Psicol. Soc & $18(1)$ \\
\hline 2006 & Cardoso, Faúndes & $\begin{array}{l}\text { Mortalidade de mulheres em idade fértil devido a causas } \\
\text { externas no Município de Cascavel, Paraná, Brasil, } 1991 \text { a } 2000\end{array}$ & Rev. Saúde Pública & $22(10)$ \\
\hline 2006 & Faúndes et al & $\begin{array}{l}\text { Violência sexual: procedimentos indicados e seus resultados no } \\
\text { atendimento de urgência de mulheres vítimas de estupro }\end{array}$ & $\begin{array}{l}\text { Rev. Bras. Ginecol. } \\
\text { Obstet. }\end{array}$ & $28(2)$ \\
\hline 2006 & $\begin{array}{l}\text { Bruschi, Paula, } \\
\text { Bordin }\end{array}$ & $\begin{array}{l}\text { Prevalência e procura de ajuda na violência conjugal física ao } \\
\text { longo da vida }\end{array}$ & Rev. Saúde Pública & $40(2)$ \\
\hline 2006 & Reichenheim et al. & $\begin{array}{l}\text { The magnitude of intimate partner violence in Brazil: portraits } \\
\text { from } 15 \text { capital cities and the Federal District }\end{array}$ & Cad. Saúde Pública & $22(2)$ \\
\hline 2006 & $\begin{array}{l}\text { Cavalcanti, Gomes, } \\
\text { Minayo }\end{array}$ & $\begin{array}{l}\text { Representacōes sociais de profissionais de saúde sobre } \\
\text { violência sexual contra a mulher: estudo em três } \\
\text { maternidades públicas municipais do Rio de Janeiro, Brasil }\end{array}$ & Cad. Saúde Pública & $22(1)$ \\
\hline 2007 & Freitas, Lima, Dytz & $\begin{array}{l}\text { Atendimento à mulher vítima de violência sexual no Programa } \\
\text { Violeta, Distrito Federal }\end{array}$ & Comun. Cienc. Saude; & $18(3)$ \\
\hline 2007 & Oliveira, Fonseca & $\begin{array}{l}\text { Práticas dos profissionais das equipes de saúde da família } \\
\text { voltadas para as mulheres em situação de violência sexual }\end{array}$ & Rev. Esc. Enferm. USP & $41(4)$ \\
\hline 2007 & Souto et al & $\begin{array}{l}\text { Tendências das pesquisas de enfermagem em saúde da mulher } \\
\text { no período de } 2001 \text { a } 2005\end{array}$ & $\begin{array}{l}\text { Texto \& Contexto } \\
\text { Enferm }\end{array}$ & $16(4)$ \\
\hline 2007 & $\begin{array}{l}\text { Kiss, Schraiber, } \\
\text { D'oliveira }\end{array}$ & $\begin{array}{l}\text { Possibilidades de uma rede intersetorial de atendimento a } \\
\text { mulheres em situaçăo de violência }\end{array}$ & $\begin{array}{l}\text { Interface Comun. } \\
\text { Saúde Educ. }\end{array}$ & $11(23)$ \\
\hline 2007 & Mattar et al. & $\begin{array}{l}\text { A violência doméstica como indicador de risco no rastreamento } \\
\text { da depressão pós-parto }\end{array}$ & $\begin{array}{l}\text { Rev. Bras. Ginecol. } \\
\text { Obstet }\end{array}$ & $29(9)$ \\
\hline 2007 & Eizlrik et al. & $\begin{array}{l}\text { Contratransferência no atendimento inicial de vítimas de } \\
\text { violência sexual e urbana: uma pesquisa qualitativa/quantitativa }\end{array}$ & $\begin{array}{l}\text { Rev. Psiquiatr. Rio } \\
\text { Gd. Sul }\end{array}$ & $29(2)$ \\
\hline 2007 & Rabello, Caldas & Violência contra a mulher, coesão familiar e drogas & Rev. Saúde Pública & $41(6)$ \\
\hline 2007 & Diniz et al & Women who were burned by their husbands or partners & Acta Paul. Enferm & $20(3)$ \\
\hline 2007 & Schraiber et al. & $\begin{array}{l}\text { Prevalência da violência contra a mulher por parceiro íntimo } \\
\text { em regiôes do Brasil }\end{array}$ & Rev. Saúde Pública & $41(5)$ \\
\hline 2007 & Oliveira, Cavalcanti & $\begin{array}{l}\text { Violência doméstica na perspectiva de gênero e políticas } \\
\text { públicas }\end{array}$ & $\begin{array}{l}\text { Rev. Bras. Crescimento } \\
\text { Desenvolv. Hum. }\end{array}$ & $17(1)$ \\
\hline 2007 & Durand, Schraiber. & $\begin{array}{l}\text { Violência na gestação entre usuárias de serviços públicos de } \\
\text { saúde da Grande São Paulo: prevalência e fatores associados }\end{array}$ & Rev. Bras. Epidemiol & $10(3)$ \\
\hline 2007 & Faúndes et al & $\begin{array}{l}\text { Relatório final: X Fórum interprofissional sobre violência } \\
\text { contra a mulher e implementaçăo do aborto previsto na lei }\end{array}$ & Femina & $35(1)$ \\
\hline
\end{tabular}




\begin{tabular}{|c|c|c|c|c|}
\hline 2007 & Meneghel Iñiguez & Contadores de histórias: práticas discursivas e violência de gênero & Cad. Saúde Pública & $23(8)$ \\
\hline 2007 & Rezende et al. & $\begin{array}{l}\text { Lesōes buco-dentais em mulheres em situação de violência: um } \\
\text { estudo piloto de casos periciados no IML de Belo Horizonte, MG }\end{array}$ & Rev. Bras. Epidemiol. & $10(2)$ \\
\hline 2007 & Monteiro, Souza & Vivência da violência conjugal: fatos do cotidiano & $\begin{array}{l}\text { Texto \& Contexto } \\
\text { Enferm. }\end{array}$ & $16(1)$ \\
\hline 2007 & Doubova et al & $\begin{array}{l}\text { Violencia de pareja en mujeres embarazadas en la Ciudad de } \\
\text { México }\end{array}$ & Rev. Saúde Pública & $41(4)$ \\
\hline 2007 & Schraiber et al & $\begin{array}{l}\text { Violência contra mulheres entre usuárias de serviços públicos } \\
\text { de saúde da Grande São Paulo }\end{array}$ & Rev. Saúde Pública & $41(3)$ \\
\hline 2007 & $\begin{array}{l}\text { Mota, Vasconcelos, } \\
\text { Assis }\end{array}$ & $\begin{array}{l}\text { Análise de correspondência como estratégia para descrição } \\
\text { do perfil da mulher vítima do parceiro atendida em serviço } \\
\text { especializado }\end{array}$ & Cienc. Saúde Coletiva & $12(3)$ \\
\hline 2007 & Diniz et al & $\begin{array}{l}\text { Women victims of sexual violence: adherence to } \\
\text { chemoprevention of HIV }\end{array}$ & $\begin{array}{l}\text { Rev. Latinoam. } \\
\text { Enferm; }\end{array}$ & $15(1)$ \\
\hline 2007 & Villela, Lago & $\begin{array}{l}\text { Conquistas e desafios no atendimento das mulheres que } \\
\text { sofreram violência sexual }\end{array}$ & Cad. Saúde Pública & $23(2)$ \\
\hline 2007 & Bedone, Faúndes & $\begin{array}{l}\text { Atendimento integral às mulheres vítimas de violência } \\
\text { sexual: Centro de Assistência Integral à Saúde da Mulher, } \\
\text { Universidade Estadual de Campinas }\end{array}$ & Cad. Saúde Pública & $42(2)$ \\
\hline 2007 & Mattar et al. & $\begin{array}{l}\text { Assistência multiprofissional à vítima de violência sexual: a } \\
\text { experiência da Universidade Federal de São Paulo }\end{array}$ & Cad. Saúde Pública & $23(2)$ \\
\hline 2007 & Oliveira & Fórum: violência sexual e saúde. Introdução & Cad. Saúde Pública & $23(2)$ \\
\hline
\end{tabular}

Quadro IV- Resumos incluídos na categoria Violência e Infância e Adolescência

\begin{tabular}{|c|c|c|c|c|}
\hline Ano & Autores & Título do artigo & Periódico & Vol. (n) \\
\hline 2003 & Taracena & $\begin{array}{l}\text { Violence sociale, violence familiale: les jeunes de la rue a Mexico } \\
\text { / Social violence, family violence: Street youth in Mexico }\end{array}$ & Pulsional Rev. Psicanal & $16(176)$ \\
\hline 2003 & Rauter & Produção social do negativo: notas introdutórias & Psicol. Clin & $15(1)$ \\
\hline 2003 & Brasil et al. & O trabalho interdisciplinar no contexto da exclusão & Psicol. Cienc. Prof & $23(3)$ \\
\hline 2003 & Carreteiro & Sofrimentos sociais em debate & Psicol. USP & $14(3)$ \\
\hline 2003 & Cavalcanti, Duarte & $\begin{array}{l}\text { Manifestacôes Bucais do Abuso Infantil em João Pessoa - } \\
\text { Paraíba - Brasil. }\end{array}$ & $\begin{array}{l}\text { Revista Brasileira De } \\
\text { Ciências Da Saúde }\end{array}$ & $7(2)$ \\
\hline 2003 & Ruzany et al & $\begin{array}{l}\text { A violência nas relaçôes afetivas dificulta a prevençäo de DST/ } \\
\text { AIDS? }\end{array}$ & J. Pediatr. (Rio J.); & $79(4)$ \\
\hline 2003 & $\begin{array}{l}\text { D’ Affonseca, } \\
\text { Williams }\end{array}$ & $\begin{array}{l}\text { Clubinho: intervenção psicoterapêutica com crianças vítimas } \\
\text { ou em risco de violência física intrafamiliar. }\end{array}$ & $\begin{array}{l}\text { Temas Sobre } \\
\text { Desenvolvimento }\end{array}$ & $12(67)$ \\
\hline 2003 & Fensterseifer, Braga & $\begin{array}{l}\text { O encontro da violência com a mentira: síndrome de } \\
\text { Munchausen por Procuraçấo. }\end{array}$ & Psico & $34(1)$ \\
\hline 2003 & Rosa, Tassara & $\begin{array}{l}\text { Em busca de um sentido para a violência doméstica contra } \\
\text { crianças. }\end{array}$ & Psicologia Argumento & $21(34)$ \\
\hline 2003 & Vagostello et al. & $\begin{array}{l}\text { Violência doméstica e escola: um estudo em escolas públicas } \\
\text { de São Paulo. }\end{array}$ & Paideia & $13(26)$ \\
\hline 2003 & Ferreira, Cartana & $\begin{array}{l}\text { A enfermagem e o cuidado de crianças vítimas de abuso e } \\
\text { exploração sexual }\end{array}$ & $\begin{array}{l}\text { Texto \& Contexto } \\
\text { Enferm }\end{array}$ & $12(2)$ \\
\hline
\end{tabular}




\begin{tabular}{|c|c|c|c|c|}
\hline 2003 & Lima & De uma juventude guerreira a aprendizes de guerra & Psicol. Clin & $15(1)$ \\
\hline 2003 & Molina & $\begin{array}{l}\text { Prostituição juvenil: uma condição existencial em busca de } \\
\text { seus sentidos }\end{array}$ & Psicol. Cienc. Prof & $23(2)$ \\
\hline 2003 & Harada, Brêtas, Silva & $\begin{array}{l}\text { Causas consequências e formas de prevenção da violência } \\
\text { doméstica contra a criança e o adolescente }\end{array}$ & Rev. Paul. Enferm & $22(3)$ \\
\hline 2003 & $\begin{array}{l}\text { Bazon, Dacanal, } \\
\text { Biasoli-Alves }\end{array}$ & $\begin{array}{l}\text { Vitimização doméstica de crianças e adolescentes: análise de } \\
\text { um serviço de acompanhamento familiar }\end{array}$ & Psico (Porto Alegre) & $34(1)$ \\
\hline 2003 & Cavalcanti & $\begin{array}{l}\text { Manifestaçóes físicas do abuso infantil: aspectos de interesse } \\
\text { odontológico }\end{array}$ & Rev. Paul. Odontol & $25(5)$ \\
\hline 2003 & Marques, Colares & A identificação do abuso infantil pelo odontopediatra & $\begin{array}{l}\text { JBC J. Bras. Clin. } \\
\text { Odontol. Integr }\end{array}$ & $7(42)$ \\
\hline 2003 & Ribeiro et al. & O papel das drogas na vida da criança em situação de rua & Rev. Ter. Ocup & $14(2)$ \\
\hline 2003 & $\begin{array}{l}\text { Oliveira, Ribeiro, } \\
\text { Albuquerque }\end{array}$ & $\begin{array}{l}\text { Notificação obrigatória da violência ou suspeita de violência } \\
\text { contra crianças e adolescentes: construindo uma rede de proteção }\end{array}$ & Divulg. Saúde Debate & 26 \\
\hline 2003 & Landini & Pedófilo, quem és? A pedofilia na mídia impressa & Cad. Saúde Pública & $19(2)$ \\
\hline 2003 & Ribeiro & A rua: um acolhimento falaz às criancas que nela vivem & Rev. Latinoam. Enferm & $11(5)$ \\
\hline 2003 & $\begin{array}{l}\text { Taquette et al } \\
\text { Ricardo, I. }\end{array}$ & Relacionamento violento na adolescência e risco de DST/AIDS & Cad. Saúde Pública & $19(5)$ \\
\hline 2003 & Pordeus, Fraga, Facó & $\begin{array}{l}\text { Açốes de prevenção dos acidentes e violências em crianças e } \\
\text { adolescentes, desenvolvidas pelo setor público de saúde de } \\
\text { Fortaleza, Ceará, Brasil }\end{array}$ & Cad. Saúde Pública & $19(4)$ \\
\hline 2003 & Polanczyk et al & $\begin{array}{l}\text { Violência sexual e sua prevalência em adolescentes de Porto } \\
\text { Alegre, Brasil }\end{array}$ & Rev. Saúde Publica & $37(1)$ \\
\hline 2004 & $\begin{array}{l}\text { Batista, Fukahori, } \\
\text { Haydu }\end{array}$ & $\begin{array}{l}\text { Filme com cenas de violência: efeito sobre o comportamento } \\
\text { agressivo de crianças expresso no enredo de uma redação. }\end{array}$ & Interação Em Psicologia & $8(1)$ \\
\hline 2004 & $\begin{array}{l}\text { Bringiotti, } \\
\text { Krynveniuk, Lasso }\end{array}$ & $\begin{array}{l}\text { As múltiplas violências da violência na escola. Desenvolvimento } \\
\text { de um enfoque teórico e metodológico integrativo. }\end{array}$ & Paideia & $14(29)$ \\
\hline 2004 & Cavalcanti, Duarte & $\begin{array}{l}\text { Perfil da criança e do adolescente vítimas de violência } \\
\text { doméstica. }\end{array}$ & $\begin{array}{l}\text { Revista Brasileira De } \\
\text { Ciências Da Saúde }\end{array}$ & $8(2)$ \\
\hline 2004 & $\begin{array}{l}\text { Chaim, Daruge, } \\
\text { Gonçalves }\end{array}$ & $\begin{array}{l}\text { Maus-tratos infantis - avaliação da capacidade de diagnóstico } \\
\text { dos cirurgiōes-dentistas. }\end{array}$ & $\begin{array}{l}\text { Revista Da Associação } \\
\text { Paulista De Cirurgiôes } \\
\text { Dentistas }\end{array}$ & $58(1)$ \\
\hline 2004 & Gomes. & $\begin{array}{l}\text { A banalização da vida, suas consequências e seus } \\
\text { condicionantes }\end{array}$ & Rev. Cienc. Med. Biol & $3(1)$ \\
\hline 2004 & $\begin{array}{l}\text { Ferriani, Garbin, } \\
\text { Ribeiro }\end{array}$ & $\begin{array}{l}\text { Caracterização de casos em que crianças e adolescentes foram } \\
\text { vítimas de abuso sexual na regiấo sudoeste da cidade de } \\
\text { Ribeiräo Preto. SP. no ano de } 2000 \text {. }\end{array}$ & $\begin{array}{l}\text { Acta Paulista De } \\
\text { Enfermagem }\end{array}$ & $17(1)$ \\
\hline 2004 & Santos, Costa & $\begin{array}{l}\text { O papel desempenhado pela justiça na história de uma família } \\
\text { com denúncia de violência sexual }\end{array}$ & $\begin{array}{l}\text { Interaçōes Estud. Pesqui. } \\
\text { Psicol }\end{array}$ & $9(17)$ \\
\hline 2004 & Cesca & $\begin{array}{l}\text { O papel do psicólogo jurídico na violência intrafamilar: } \\
\text { possíveis articulaçōes }\end{array}$ & Psicol. Soc & $16(3)$ \\
\hline 2004 & $\begin{array}{l}\text { Noguchi, Assis, } \\
\text { Santos. }\end{array}$ & $\begin{array}{l}\text { ntre quatro paredes: atendimento fonoaudiológico a crianças e } \\
\text { adolescentes vítimas de violência. }\end{array}$ & Ciência \& Saúde Coletiva & $9(4)$ \\
\hline 2004 & Leme & $\begin{array}{l}\text { Resolução de conflitos interpessoais: interaçôes entre cognição } \\
\text { e afetividade na cultura }\end{array}$ & Psicol. Reflex. Crit & $17(3)$ \\
\hline 2004 & Vendrúscolo et al. & As políticas sociais e a violência: uma proposta de Ribeirão Preto & Rev. Latinoam. Enferm; & $12(3)$ \\
\hline
\end{tabular}




\begin{tabular}{|c|c|c|c|c|}
\hline 2004 & Njaine, Minayo & $\begin{array}{l}\text { A violência na mídia como tema da área da saúde pública: } \\
\text { revisão da literatura }\end{array}$ & Cienc. Saúde Coletiva & $9(1)$ \\
\hline 2004 & Ribeiro, Ferriani, Reis & $\begin{array}{l}\text { Violência sexual contra crianças e adolescentes: características } \\
\text { relativas à vitimização nas relaçôes familiares. }\end{array}$ & Cad. Saúde Pública & $20(2)$ \\
\hline 2004 & Rosa, Tassara & $\begin{array}{l}\text { Violência, ética e direito: implicaçôes para o reconhecimento } \\
\text { da violência doméstica contra crianças. }\end{array}$ & $\begin{array}{l}\text { Psicologia, Ciência E } \\
\text { Profissão }\end{array}$ & $24(3)$ \\
\hline 2004 & Vieira et al. & $\begin{array}{l}\text { Caracterização da violência física contra crianças e } \\
\text { adolescentes. }\end{array}$ & Revista Enfermagem Uerj & $12(13)$ \\
\hline 2004 & $\begin{array}{l}\text { Canabarro, Eidt, } \\
\text { Aerts }\end{array}$ & Traumas infantis ocorridos em domicílio & Rev. Gauch. Enferm & $25(2)$ \\
\hline 2004 & De Biasil, Penna & Violência e maus tratos na infância: o olhar das crianças & REME Rev. Min. Enferm & $8(4)$ \\
\hline 2004 & Gomes et al. & $\begin{array}{l}\text { As sombras da violência doméstica contra crianças e } \\
\text { adolescentes à luz de Pierre Bordieu }\end{array}$ & Rev. Enferm. UERJ & $12(2)$ \\
\hline 2004 & Sudbrack & O extermínio de meninos de rua no Brasil & São Paulo Perspect. & $18(1)$ \\
\hline 2004 & $\begin{array}{l}\text { Brancalhone, Fogo, } \\
\text { Willians }\end{array}$ & $\begin{array}{l}\text { Crianças expostas à violência conjugal: avaliação do } \\
\text { desempenho acadêmico }\end{array}$ & Psicol. Teor. Pesqui; & $20(2)$ \\
\hline 2005 & Andrade et al. & $\begin{array}{l}\text { Avaliação da conduta dos odontopediatras de Recife com } \\
\text { relação ao abuso infantil. }\end{array}$ & Revista Odonto Ciência & $20(49)$ \\
\hline 2005 & Brito et al. & $\begin{array}{l}\text { Violência doméstica contra crianças e adolescentes: estudo de } \\
\text { um programa de intervençấo. }\end{array}$ & Ciência \& Saúde Coletiva & $10(1)$ \\
\hline 2005 & Azambuja & Violência doméstica: reflexōes sobre o agir profissional & Psicol. Cienc. Prof & $25(1$ \\
\hline 2005 & $\begin{array}{l}\text { Delfino, Biasoli-Alves, } \\
\text { Sagim }\end{array}$ & $\begin{array}{l}\text { A identificação da violência doméstica e da negligência por pais } \\
\text { de camada média e popular }\end{array}$ & $\begin{array}{l}\text { Texto \& Contexto } \\
\text { Enferm }\end{array}$ & $\begin{array}{c}14(\mathrm{n} \\
\text { especial })\end{array}$ \\
\hline 2005 & Salcedo, Carvalho & Maltrato infantil por agresores bajo efecto del alcohol. & $\begin{array}{l}\text { Revista Latino-Americana } \\
\text { De Enfermagem }\end{array}$ & $13(\mathrm{n})$ \\
\hline 2005 & Schwanck et al. & $\begin{array}{l}\text { A percepção de formandos de enfermagem acerca da violência } \\
\text { contra a criança }\end{array}$ & Cogitare Enferm & $10(2)$ \\
\hline 2005 & Cunha, Assis, Pacheco & $\begin{array}{l}\text { A enfermagem e a atenção à criança vítima de violência } \\
\text { familiar }\end{array}$ & Rev. Bras. Enferm & $58(4)$ \\
\hline 2005 & Phebo, Moura & Violência urbana: um desafio para o pediatra & J. Pediatr. (Rio J.) & $81(5)$ \\
\hline 2005 & Rivera-Rivera et al & $\begin{array}{l}\text { Intra-familial physical violence among Mexican and Egyptian } \\
\text { youth }\end{array}$ & Rev. Saude Publica & $39(5)$ \\
\hline 2005 & Coelho Junior & Um estudo sobre a violência em duas histórias gráficas & $\begin{array}{l}\text { Rev. Bras. Crescimento } \\
\text { Desenvolv. Hum }\end{array}$ & $15(2)$ \\
\hline 2005 & Paludo, Koller & $\begin{array}{l}\text { Quem săo as crianças que estão nas ruas: vítimas ou } \\
\text { vitimizadoras? }\end{array}$ & Interacao Psicol & $9(1)$ \\
\hline 2005 & $\begin{array}{l}\text { Pavarino, Prette, } \\
\text { Prette, }\end{array}$ & $\begin{array}{l}\text { O desenvolvimento da empatia como prevenção da } \\
\text { agressividade na infância }\end{array}$ & Psico (Porto Alegre) & $36(2)$ \\
\hline 2005 & Vasconcelos et al. & $\begin{array}{l}\text { Contribuição dos fatores de risco psicossociais para o } \\
\text { transtorno de déficit de atenção/hiperatividade }\end{array}$ & Arq. Neuropsiquiatr & $63(1)$ \\
\hline 2005 & Gomes, Fonseca & $\begin{array}{l}\text { Dimensôes da violência contra crianças e adolescentes, } \\
\text { apreendidas do discurso de professoras e cuidadoras }\end{array}$ & $\begin{array}{l}\text { Texto \& Contexto } \\
\text { Enferm }\end{array}$ & $14(\mathrm{n}$ esp) \\
\hline 2005 & Algeri & $\begin{array}{l}\text { A violência infantil na perspectiva do enfermeiro: uma questão } \\
\text { de saúde e educaçấo }\end{array}$ & Rev. Gauch. Enferm & $26(3)$ \\
\hline
\end{tabular}




\begin{tabular}{|c|c|c|c|c|}
\hline 2005 & Oliveira, Marcon & $\begin{array}{l}\text { Exploraçāo sexual infanto juvenil: causas, consequências e } \\
\text { aspectos relevantes para o profissional de saúde }\end{array}$ & Rev. Gauch. Enferm & $26(3)$ \\
\hline 2005 & Paixão, Deslandes & A Relação médico-paciente diante do abuso sexual infantil & Femina & $33(10)$ \\
\hline 2005 & $\begin{array}{l}\text { Rocha, Prado, } \\
\text { Kusahara }\end{array}$ & $\begin{array}{l}\text { O brinquedo terapêutico como um modo de cuidar de crianças } \\
\text { vítimas de violência }\end{array}$ & Cienc. Cuid. Saude & $4(2)$ \\
\hline 2005 & Costa, Penso, Almeida & $\begin{array}{l}\text { O grupo multifamiliar como um método de intervenção em } \\
\text { situaçōes de abuso sexual infantil }\end{array}$ & Psicol. USP & $16(4)$ \\
\hline 2005 & $\begin{array}{l}\text { Camargo, Alves, } \\
\text { Quirino }\end{array}$ & $\begin{array}{l}\text { Violência contra crianças e adolescentes negros: uma } \\
\text { abordagem histórica }\end{array}$ & $\begin{array}{l}\text { Texto \& Contexto } \\
\text { Enferm }\end{array}$ & $14(4)$ \\
\hline 2005 & Muller, , Weigelt & Família com criança vítima de agravos por causas externas & Cogitare Enferm & $10(2)$ \\
\hline 2005 & Pires, Miyazaki & $\begin{array}{l}\text { Maus-tratos contra crianças e adolescentes: revisão da } \\
\text { literatura para profissionais da saúde }\end{array}$ & Arq. Cienc. Saude & 12(1) \\
\hline 2005 & Algeri, Souza & $\begin{array}{l}\text { Violência intrafamiliar contra a criança: uma análise crítico- } \\
\text { reflexiva para a equipe de enfermagem }\end{array}$ & $\begin{array}{l}\text { Fonte: Online Braz. J. } \\
\text { Nurs. }\end{array}$ & $4(3)$ \\
\hline 2005 & Lopes Neto & Bullying: comportamento agressivo entre estudantes & J. Pediatr. (Rio J.) & $81(5)$ \\
\hline 2005 & Martins, Andrade & $\begin{array}{l}\text { Causas externas entre menores de } 15 \text { anos em cidade do sul do } \\
\text { Brasil: atendimentos em pronto-socorro, internaçốes e óbitos }\end{array}$ & Rev. Bras. Epidemiol & $8(2)$ \\
\hline 2005 & Maldonado, Williams & $\begin{array}{l}\text { O comportamento agressivo de crianças do sexo masculino na } \\
\text { escola e sua relação com a violência doméstica }\end{array}$ & Psicol. Estud & $10(3)$ \\
\hline 2005 & Parreira et al. & A criança abrigada: consideraçōes acerca do sentido da filiação & Psicol. Estud & $10(2)$ \\
\hline 2005 & & $\begin{array}{l}\text { Evoluçāo da mortalidade por causas violentas em crianças e } \\
\text { adolescentes, Feira de Santana, Brasil }\end{array}$ & $\begin{array}{l}\text { Rev. Baiana Saude } \\
\text { Publica }\end{array}$ & $29(1)$ \\
\hline 2005 & Martins, Andrade & $\begin{array}{l}\text { Epidemiologia dos acidentes e violências entre menores de } 15 \\
\text { anos em município da região sul do Brasil }\end{array}$ & Rev. Latinoam. Enferm & $13(4)$ \\
\hline 2005 & Moura, Reichenheim & $\begin{array}{l}\text { Estamos realmente detectando violência familiar contra a } \\
\text { criança em serviços de saúde? A experiência de um serviço } \\
\text { público do Rio de Janeiro, Brasil }\end{array}$ & Cad. Saúde Pública & $21(4)$ \\
\hline 2005 & Assis, Constantino & Perspectivas de prevenção da infraçăo juvenil masculina & Cienc. Saúde Coletiva & $10(1)$ \\
\hline 2005 & Farias & Violência contra bebês & Rev. Bras. Psicanal & $39(3)$ \\
\hline 2005 & $\begin{array}{l}\text { Ortiz-Hernández, } \\
\text { García Torres. }\end{array}$ & $\begin{array}{l}\text { Efectos de la violencia y la discriminación en la salud mental de } \\
\text { bisexuales, lesbianas y homosexuales de la Ciudad de México }\end{array}$ & Cad. Saúde Pública & $21(3)$ \\
\hline 2006 & Algeri, Souza & $\begin{array}{l}\text { Violence against children and adolescents: a challenge in the } \\
\text { daily work of the nursing team. }\end{array}$ & $\begin{array}{l}\text { Revista Latino-Americana } \\
\text { De Enfermagem }\end{array}$ & $14(4)$ \\
\hline 2006 & Chaim, Gonçalves & $\begin{array}{l}\text { A responsabilidade ética e legal do cirurgião-dentista em } \\
\text { relaçẫo à criança maltratada. }\end{array}$ & Revista ABO Nacional & $14(1)$ \\
\hline 2006 & Flores, Schirmer & Violência intrafamiliar na adolescência na cidade de Puno - Peru & $\begin{array}{l}\text { Revista Latino-Americana } \\
\text { De Enfermagem }\end{array}$ & $14(4)$ \\
\hline 2006 & Granville-Garcia et al & $\begin{array}{l}\text { Ocorrência de maus-tratos em crianças e adolescentes na } \\
\text { cidade de Caruarú-PE. }\end{array}$ & $\begin{array}{l}\text { Pesquisa Brasileira } \\
\text { em Odontopediatria e } \\
\text { Clínica Integrada }\end{array}$ & $6(1)$ \\
\hline 2006 & Habigzang et al. & $\begin{array}{l}\text { Fatores de risco e de proteção na rede de atendimento a } \\
\text { crianças e adolescentes vítimas de violência sexual. }\end{array}$ & $\begin{array}{l}\text { Psicologia: Reflexão e } \\
\text { Crítica }\end{array}$ & $19(3)$ \\
\hline 2006 & Lima et al & $\begin{array}{l}\text { Experiências de violência intrafamiliar entre adolescentes em } \\
\text { conflito com a lei. }\end{array}$ & $\begin{array}{l}\text { Revista Brasileira de } \\
\text { Crescimento e Desenvol- } \\
\text { vimento Humano }\end{array}$ & $16(2)$ \\
\hline
\end{tabular}




\begin{tabular}{|c|c|c|c|c|}
\hline 2006 & Oliveira, Antonio & $\begin{array}{l}\text { Sentimentos do adolescente relacionados ao fenômeno bullying: } \\
\text { possibilidades para a assistencia de enfermagem nesse contexto. }\end{array}$ & $\begin{array}{l}\text { Revista Eletrônica de } \\
\text { Enfermagem }\end{array}$ & $8(1)$ \\
\hline 2006 & Rocha, Ferreira & $\begin{array}{l}\text { Queixas identificadas em crianças e adolescentes atendidos } \\
\text { pelo serviço de psicologia pediátrica de um hospital } \\
\text { universitário. }\end{array}$ & $\begin{array}{l}\text { Revista Brasileira de } \\
\text { Crescimento e Desenvol- } \\
\text { vimento Humano }\end{array}$ & $16(1)$ \\
\hline 2006 & $\begin{array}{l}\text { Rodrigues, Brino, } \\
\text { Williams }\end{array}$ & $\begin{array}{l}\text { Concepçôes de sexualidade entre adolescentes com e sem } \\
\text { histórico de violência sexual. }\end{array}$ & Paideia & $16(34)$ \\
\hline 2006 & Suárez, Menkes & $\begin{array}{l}\text { La violencia familiar ejercida en contra de los adolescentes } \\
\text { mexicanos. }\end{array}$ & Revista de Saúde Pública & $40(4)$ \\
\hline 2006 & Vasconcelos, Souza & $\begin{array}{l}\text { As noçôes de educação e disciplina em pais que agridem seus } \\
\text { filhos. }\end{array}$ & Psico & $37(1)$ \\
\hline 2006 & Pizzetti & $\begin{array}{l}\text { Cadeiras vazias: violência e desamparo. Consideraçôes em } \\
\text { torno de um trabalho de consultoria }\end{array}$ & Pulsional Rev. Psicanal & $19(187)$ \\
\hline 2006 & $\begin{array}{l}\text { Beraldo, Capitão, } \\
\text { Oliveira. }\end{array}$ & Indicadores sexuais no desenho da figura humana e abuso sexual & Aval. Psicol & $5(1)$ \\
\hline 2006 & Guirado & $\begin{array}{l}\text { A psicanálise dentro dos muros de instituiçōes para jovens em } \\
\text { conflito com a lei }\end{array}$ & Bol. Psicol & $56(124)$ \\
\hline 2006 & Souza, Sperb,. & $\begin{array}{l}\text { Assimetria entre paz, guerra e violência na concepção de } \\
\text { crianças e adolescentes }\end{array}$ & Psico USF & $11(2)$ \\
\hline 2006 & Pimentel, Araujo & Violência sexual intrafamiliar & Rev. Para. Med & 20(3) \\
\hline 2006 & Fonseca, Lima, Morato & Adolescência, violência e desamparo: uma articulaçăo possível? & Encontro & $10(13)$ \\
\hline 2006 & Narvaz, Koller, & A concepção de família de uma mulher-mãe de vítimas de incesto & Psicol. Reflex. Crit & $19(3)$ \\
\hline 2006 & Santos et al. & $\begin{array}{l}\text { Maus-tratos infantis: conhecimento e atitudes de } \\
\text { odontopediatras de Uberlândia e Araguari, Minas Gerais }\end{array}$ & $\begin{array}{l}\text { Pesqui. Bras. } \\
\text { Odontopediatria Clin. } \\
\text { Integr }\end{array}$ & $6(3)$ \\
\hline 2006 & Nogueira, Bellini & $\begin{array}{l}\text { Sexualidade e violencia, o que é isso para jovens que vivem } \\
\text { na rua? }\end{array}$ & $\begin{array}{l}\text { Texto \& Contexto } \\
\text { Enferm }\end{array}$ & $15(4)$ \\
\hline 2006 & $\begin{array}{l}\text { Cardoso, Santana, } \\
\text { Ferriani }\end{array}$ & $\begin{array}{l}\text { Criança e adolescente vítimas de maus-tratos: informaçôes dos } \\
\text { enfermeiros de um hospital público }\end{array}$ & Rev. Enferm. UERJ & $14(4)$ \\
\hline 2006 & Grangeiro, Silva & $\begin{array}{l}\text { Mortalidade por causas externas em adolescentes no estado do } \\
\text { Ceará, Brasil }\end{array}$ & $\begin{array}{l}\text { An. Fac. Med. Univ. Fed. } \\
\text { Pernamb }\end{array}$ & $51(1)$ \\
\hline 2006 & Njaine. & $\begin{array}{l}\text { Sentidos da violência ou a violência sem sentido: o olhar dos } \\
\text { adolescentes sobre a mídia }\end{array}$ & $\begin{array}{l}\text { Interface Comun. Saude } \\
\text { Educ }\end{array}$ & $10(20)$ \\
\hline 2006 & Val, Tambellini & $\begin{array}{l}\text { A violência do trabalho infantil: aspectos sanitários, políticos, } \\
\text { jurídico-legais e sociais - uma revisão da literatura }\end{array}$ & $\begin{array}{l}\text { Cad. Saúde Colet., } \\
\text { (Rio J.) }\end{array}$ & $14(1)$ \\
\hline 2006 & Ricas, Donoso, Gresta & A violência na infância como uma questão cultural & $\begin{array}{l}\text { Texto \& Contexto } \\
\text { Enferm }\end{array}$ & $15(1)$ \\
\hline 2006 & Morales Ruiz et al. & $\begin{array}{l}\text { Conciencia sobre intimidación en la formación de maestras } \\
\text { de párvulos }\end{array}$ & Rev. Interam. Psicol & $40(1)$ \\
\hline 2006 & Zavaschi et al. & $\begin{array}{l}\text { Transtornos do humor no adulto e trauma psicológico na } \\
\text { infância }\end{array}$ & Rev. Bras. Psiquiatr & $28(3)$ \\
\hline 2006 & Tuppy, & $\begin{array}{l}\text { Educadores da paz: a experiência do interação na região de } \\
\text { Araçatuba (SP) }\end{array}$ & Divulg. Saude Debate & 35 \\
\hline 2006 & Carmo, Harada & Physical violence as educational practice & Rev. Latinoam. Enferm & $21(3)$ \\
\hline 2007 & $\begin{array}{l}\text { Aded, Dalcin, } \\
\text { Cavalcanti, }\end{array}$ & $\begin{array}{l}\text { Estudo da incidência de abuso sexual contra crianças no Rio } \\
\text { de Janeiro }\end{array}$ & Cad. Saúde Pública & $23(8)$ \\
\hline
\end{tabular}




\begin{tabular}{|c|c|c|c|c|}
\hline 2007 & Grudtner, Carraro & $\begin{array}{l}\text { Violência intrafamiliar contra a criança e o adolescente: } \\
\text { reflexôes sobre o cuidado de enfermeiras. }\end{array}$ & $\begin{array}{l}\text { Texto \& Contexto- } \\
\text { Enfermagem }\end{array}$ & $16(1)$ \\
\hline 2007 & Santos, Ferriani & $\begin{array}{l}\text { A violência familiar no mundo da criança de creche e pré- } \\
\text { escola. }\end{array}$ & $\begin{array}{l}\text { Revista Brasileira de } \\
\text { Enfermagem }\end{array}$ & $60(5)$ \\
\hline 2007 & Silva & Sujeito e objeto na delinquência juvenil & Pulsional Rev. Psicanal; & $20(189)$ \\
\hline 2007 & Martins et al. & $\begin{array}{l}\text { Family dynamics from the perspective of parents and children } \\
\text { involved in domestic violence against children and adolescents }\end{array}$ & Rev. Latinoam. Enferm; & $15(5)$ \\
\hline 2007 & Monteiro et al. & A violência intra-familiar contra adolescentes grávidas & Rev. Bras. Enferm & $60(4)$ \\
\hline 2007 & $\begin{array}{l}\text { Vendruscolo, Ferriani, } \\
\text { Silva }\end{array}$ & $\begin{array}{l}\text { Public care policies for child and adolescent victims of } \\
\text { domestic violence }\end{array}$ & Rev. Latinoam. Enferm & $15(\mathrm{n})$ \\
\hline 2007 & Jucá, et al. & $\begin{array}{l}\text { Significando a morte, através de redes sociais, em um contexto } \\
\text { de vulnerabilidade social: um estudo com crianças pré- } \\
\text { escolares, seus pais e professores }\end{array}$ & Psicol. Soc & $19(2)$ \\
\hline 2007 & Scherer, Scherer & $\begin{array}{l}\text { Reflections on the care delivered in a suspected case of } \\
\text { infanticide }\end{array}$ & Rev. Latinoam. Enferm & $15(4)$ \\
\hline 2007 & Roque, Ferriani & $\begin{array}{l}\text { A study about families of children and teenagers who were } \\
\text { victims of violence and faced judicial intervention }\end{array}$ & Rev. Latinoam. Enferm & $15(4)$ \\
\hline 2007 & $\begin{array}{l}\text { Costa, Ludemir, } \\
\text { Avelar }\end{array}$ & $\begin{array}{l}\text { Violência contra adolescentes: diferenciais segundo estratos de } \\
\text { condição de vida e sexo }\end{array}$ & Cienc. Saude Coletiva & $12(5)$ \\
\hline 2007 & Ribeiro et al. & $\begin{array}{l}\text { Castigo físico adotado por pais acompanhantes no } \\
\text { disciplinamento de crianças e adolescentes }\end{array}$ & Acta Paul. Enferm & $20(3)$ \\
\hline 2007 & Priuli Moraes & Adolescentes em conflito com a lei & Cienc. Saúde Coletiva & $12(5)$ \\
\hline 2007 & Melo et al. & $\begin{array}{l}\text { A Violência rompendo interaçôes: as interações superando a } \\
\text { violência }\end{array}$ & $\begin{array}{l}\text { Rev. Bras. Saude Matern. } \\
\text { Infant; }\end{array}$ & $7(1)$ \\
\hline 2007 & Silva, Ferriani & Domestic violence: from the visible to the invisible & Rev. Latinoam. Enferm; & $15(2)$ \\
\hline
\end{tabular}

\section{Quadiro V- Resumos incluídos na categoria Violência e Situações Específicas}

\begin{tabular}{|l|l|l|l|c|}
\hline Ano & \multicolumn{1}{|c|}{ Autores } & \multicolumn{1}{|c|}{ Título do artigo } & \multicolumn{1}{|c|}{ Periódico } & Vol (n) \\
\hline 2003 & $\begin{array}{l}\text { Anser, Joly, } \\
\text { Vendramini }\end{array}$ & $\begin{array}{l}\text { Avaliação do conceito de violência no ambiente escolar: visão } \\
\text { do professor }\end{array}$ & Psicol. Teor. Prat & $5(2)$ \\
\hline 2003 & Campos & O consumo da violência: efeitos da pós modernidade & Curinga & $1(19)$ \\
\hline 2003 & Dias, Ramos & $\begin{array}{l}\text { O "des"cuidado em saúde: a violência no processo de trabalho } \\
\text { em enfermagem }\end{array}$ & $\begin{array}{l}\text { Texto \& Contexto } \\
\text { Enferm }\end{array}$ & $12(1)$ \\
\hline 2003 & Fernandes Neto et al & $\begin{array}{l}\text { Mortalidade por violência interpessoal no município de } \\
\text { Campinas, ano 2000 }\end{array}$ & Rev. Bras. Psicanal & $37(2 / 3)$ \\
\hline 2003 & Josef, Silva & $\begin{array}{l}\text { Homicídio: aspectos epidemiológicos, fenomenológicos e } \\
\text { vitimológicos }\end{array}$ & J. Bras. Psiquiatr & $12(4)$ \\
\hline 2003 & Josef, Silva & $\begin{array}{l}\text { Doença mental e comportamento violento: novas evidências } \\
\text { da pesquisa }\end{array}$ & J. Bras. Psiquiatr & $52(4)$ \\
\hline 2003 & Moraes et al. & $\begin{array}{l}\text { Tendências da mortalidade por causas externas, em Säo Luís, } \\
\text { MA, de 1980 a 1999 }\end{array}$ & Rev. Bras. Epidemiol & 6(3) \\
\hline
\end{tabular}




\begin{tabular}{|c|c|c|c|c|}
\hline 2003 & Njaine, Minayo & Violência na escola: identificando pistas para a prevenção & $\begin{array}{l}\text { Interface Comun. Saúde } \\
\text { Educ }\end{array}$ & $7(13)$ \\
\hline 2003 & Nogueira & $\begin{array}{l}\text { Drogas e violência: consideraçôes sobre um fracasso } \\
\text { civilizatório e superegóico }\end{array}$ & Pulsional Rev. Psicanal & $16(171)$ \\
\hline 2003 & Ramos, Novo & Mídia, violência e alteridade: um estudo de caso & Estud. Psicol. (Natal) & $8(3)$ \\
\hline 2003 & Reis & $\begin{array}{l}\text { Os espectadores de futebol e a problemática da violência } \\
\text { relacionada à organização do espetáculo futebolístico }\end{array}$ & Rev. Paul. Educ. Fis & $17(2)$ \\
\hline 2003 & $\begin{array}{l}\text { Ribeiro, Erdtmann, } \\
\text { Nitschke }\end{array}$ & $\begin{array}{l}\text { A excêntrica família de Antônia: imagens da família } \\
\text { contemporânea }\end{array}$ & $\begin{array}{l}\text { Texto \& Contexto } \\
\text { Enferm }\end{array}$ & $12(3)$ \\
\hline 2003 & Ristum, Bastos & $\begin{array}{l}\text { Violência urbana: uma análise dos conceitos de professores do } \\
\text { ensino fundamental }\end{array}$ & Paideia (Ribeirao Preto) & $9(1)$ \\
\hline 2003 & Sei et al. & $\begin{array}{l}\text { Atenção psicossocial à mulher e criança vitimizada: uma } \\
\text { experiência }\end{array}$ & Rev. SPAGESP & $14(4)$ \\
\hline 2003 & $\begin{array}{l}\text { Silva, Panhoca, } \\
\text { Blachman }\end{array}$ & $\begin{array}{l}\text { Traumatismos faciais causados pela violência ocorrida na } \\
\text { cidade de São Paulo, ao longo do século XX }\end{array}$ & Rev. Odontol. UNESP & $32(2)$ \\
\hline 2003 & Souza Junior et al & $\begin{array}{l}\text { Características epidemiológicas do trauma raquimedular na } \\
\text { Amazônia: Análise prospectiva de } 250 \text { casos }\end{array}$ & J. Bras. Neurocir & $14(3)$ \\
\hline 2003 & Souza & Televisão, violência e efeitos midiáticos & Psicol. Cienc. Pro & $23(4)$ \\
\hline 2003 & $\begin{array}{l}\text { Vieira, Vieira, } \\
\text { Zimmermann }\end{array}$ & $\begin{array}{l}\text { Mortalidade e anos potenciais de vida perdidos por acidentes } \\
\text { de trânsito }\end{array}$ & $\begin{array}{l}\text { Rev. Baiana Saúde } \\
\text { Publica }\end{array}$ & $27(2)$ \\
\hline 2004 & Abdalla-Filho & Violência em saúde: quando o médico é o vulnerável & Bioética & $12(2)$ \\
\hline 2003 & Ristum, Bastos & $\begin{array}{l}\text { A violência urbana e o papel da mídia na concepção de } \\
\text { professoras do ensino fundamental }\end{array}$ & Ciência e Saúde Coletiva & $13(26)$ \\
\hline 2004 & Aléssio & $\begin{array}{l}\text { A representação social da violência na literatura de cordel sobre } \\
\text { cangaço }\end{array}$ & Psicol. Cienc. Prof & $24(4)$ \\
\hline 2004 & $\begin{array}{l}\text { Aquino, Gajardo, } \\
\text { Nasello }\end{array}$ & $\begin{array}{l}\text { Baixas concentraçốes de colesterol: suas relaçôes com } \\
\text { comportamento de risco }\end{array}$ & RBM Rev. Bras. Med & $61(3)$ \\
\hline 2004 & Belo & Os efeitos da violência na constituição do sujeito psíquico & Psyche (São Paulo) & $8(15)$ \\
\hline 2004 & Calazans & $\begin{array}{l}\text { Mulheres no policiamento ostensivo e a perspectiva de uma } \\
\text { segurança cidadã }\end{array}$ & São Paulo Perspect. & $18(1)$ \\
\hline 2004 & Cerqueira, Noronha & $\begin{array}{l}\text { Cenas de linchamento: reconstruçōes dramáticas da violência } \\
\text { coletiva }\end{array}$ & Psicol. Estud & $9(2)$ \\
\hline 2004 & Chaves, Costa, Alves & $\begin{array}{l}\text { O trabalho policial: resultado de um levantamento de dados } \\
\text { em uma delegacia especializada de proteção ao idoso }\end{array}$ & $\begin{array}{l}\text { Rev. Bras. Crescimento } \\
\text { Desenvolv. Hum }\end{array}$ & $14(2)$ \\
\hline 2004 & Costa & $\begin{array}{l}\text { Ofício de polícia, violência policial e luta por cidadania em } \\
\text { Mato Grosso }\end{array}$ & São Paulo Perspect. & $18(1)$ \\
\hline 2004 & Criszóstomo, Nery & $\begin{array}{l}\text { Saúde reprodutiva: as relaçôes de gênero no planejamento } \\
\text { familiar }\end{array}$ & $\begin{array}{l}\text { Esc. Anna Nery Rev. } \\
\text { Enferm; }\end{array}$ & $8(3)$ \\
\hline 2004 & $\begin{array}{l}\text { Gawryszewski, } \\
\text { Koizumi, Mello-Jorge }\end{array}$ & $\begin{array}{l}\text { As causas externas no Brasil no ano 2000: comparando a } \\
\text { mortalidade e a morbidade }\end{array}$ & Cad. Saúde Pública & $20(4)$ \\
\hline 2004 & $\begin{array}{l}\text { Hennington } \\
\text { Cordeiro, Morera }\end{array}$ & Trabalho, violência e morte em Campinas, São Paulo, Brasil & Cad. Saúde Pública & $20(2)$ \\
\hline 2004 & Jorge & Violência urbana e impacto na saúde das populaçôes & Mundo Saúde & $28(1)$ \\
\hline 2004 & Porto & $\begin{array}{l}\text { Polícia e violência: representaçôes sociais de elites policiais do } \\
\text { Distrito Federal }\end{array}$ & São Paulo Perspect. & $18(1)$ \\
\hline
\end{tabular}




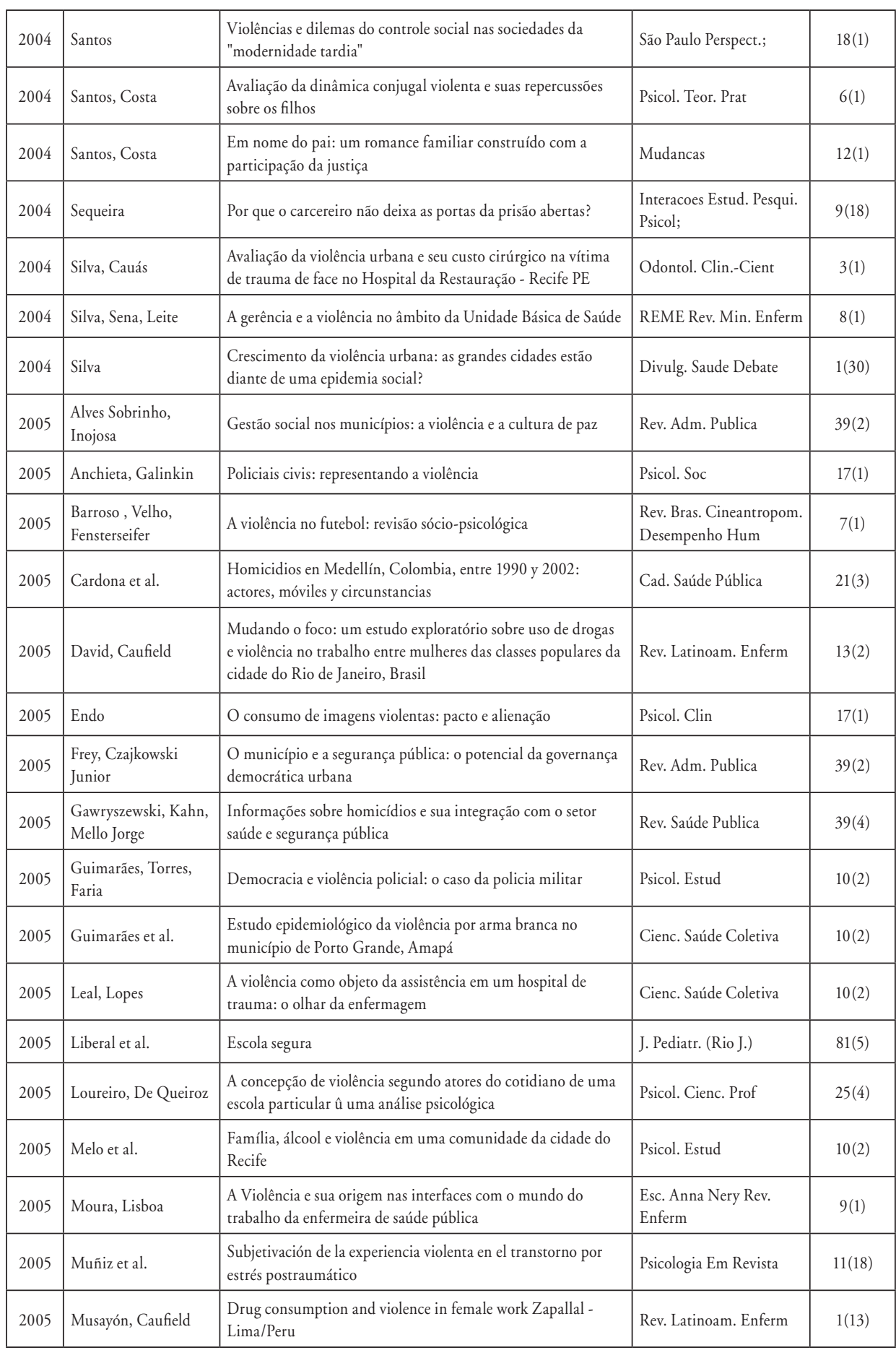




\begin{tabular}{|c|c|c|c|c|}
\hline 2005 & Nunes & $\begin{array}{l}\text { Idiomas culturais como estratégias populares para enfrentar a } \\
\text { violência urbana }\end{array}$ & Cienc. Saude Coletiva & $10(2)$ \\
\hline 2005 & Nunes, Paim & $\begin{array}{l}\text { Um estudo etno-epidemiológico da violência urbana na cidade } \\
\text { de Salvador, Bahia, Brasil: os atos de extermínio como objeto } \\
\text { de análise }\end{array}$ & Cad. Saúde Pública & $21(2)$ \\
\hline 2005 & Oliveira & Juventude, transgressão e violência: a clínica do desafio & Tempo Psicanal & $37(1)$ \\
\hline 2005 & Patrocínio et al & $\begin{array}{l}\text { Fratura de mandíbula: análise de } 293 \text { pacientes tratados no } \\
\text { Hospital de Clínicas da Universidade Federal de Uberlândia }\end{array}$ & $\begin{array}{l}\text { Rev. Bras. } \\
\text { Otorrinolaringol }\end{array}$ & $71(5)$ \\
\hline 2005 & Poyares et al. & Violência durante o sono & Rev. Bras. Psiquiatr & $27(1)$ \\
\hline 2005 & Santos Júnior, Dias & $\begin{array}{l}\text { Médicos vítimas da violência no trabalho em unidades de } \\
\text { pronto atendimento }\end{array}$ & Cad. Saúde Pública & $13(3)$ \\
\hline 2005 & Sarti & $\begin{array}{l}\text { O Atendimento de emergência a corpos feridos por atos } \\
\text { violentos }\end{array}$ & Physis (Rio J.) & $15(1)$ \\
\hline 2005 & Silva, Panhoca & A violência ocorrida na cidade de São Paulo ao longo de século XX & Salusvita & $24(1)$ \\
\hline 2005 & Soares & $\begin{array}{l}\text { Verdade e reconciliação: a menina que se salvou da violência } \\
\text { agarrando-se ao símbolo }\end{array}$ & Rev. Bras. Psicanal & $39(4)$ \\
\hline 2005 & Souza & $\begin{array}{l}\text { Masculinidade e violência no Brasil: contribuiçōes para a } \\
\text { reflexão no campo da saúde }\end{array}$ & Cienc. Saude Coletiva & $10(1)$ \\
\hline 2005 & Souza, Minayo & $\begin{array}{l}\text { Policial, risco como profissăo: morbimortalidade vinculada } \\
\text { ao trabalho }\end{array}$ & Cienc. Saude Coletiva & $10(4)$ \\
\hline 2005 & Souza, Ristum, & $\begin{array}{l}\text { Relatos de violência, concepçôes de violência e práticas } \\
\text { escolares de professoras: em busca de relaçốes }\end{array}$ & Paideia (Ribeirao Preto) & $15(32)$ \\
\hline 2005 & Velloso et al. & $\begin{array}{l}\text { A visão dos profissionais de saúde sobre a violência no } \\
\text { cotidiano de trabalho em uma Unidade Básica }\end{array}$ & REME Rev. Min. Enferm & $9(4)$ \\
\hline 2006 & Almeida, R M & $\begin{array}{l}\text { Entre o excesso e a falha: consideraçóes sobre o desalojamento } \\
\text { contemporâneo }\end{array}$ & Pulsional Rev. Psicanal; & $19(187)$ \\
\hline 2006 & Alonso Castillo et al. & $\begin{array}{l}\text { Consumo de drogas y violencia laboral en mujeres que } \\
\text { trabajan, un estudio multicéntrico: México, Perú, Brasil }\end{array}$ & Rev. Latinoam. Enferm & $14(2)$ \\
\hline 2006 & Batista & $\begin{array}{l}\text { Saúde, cultura e paz e não-violência na construção de uma } \\
\text { sociedade sustentável }\end{array}$ & Divulg. Saude Debate & $1(35)$ \\
\hline 2006 & Biancarelli & $\begin{array}{l}\text { Políticas públicas para a paz e a não-violência: os caminhos de } \\
\text { Diadema (SP) }\end{array}$ & Divulg. Saúde Debate & $1(35)$ \\
\hline 2006 & Cezar, Marziale & $\begin{array}{l}\text { Problemas de violência ocupacional em um servico de urgência } \\
\text { hospitalar da Cidade de Londrina, Paraná, Brasil }\end{array}$ & Cad. Saúde Pública & $22(1)$ \\
\hline 2006 & Costa, Marziale & $\begin{array}{l}\text { Relação tempo-violência no trabalho de enfermagem em } \\
\text { Emergência e Urgência }\end{array}$ & Rev. Bras. Enferm & $59(3)$ \\
\hline 2006 & Crowe, Ferreira & Jardim Angela: em defesa da vida & Divulg. Saúde Debate & $1(35)$ \\
\hline 2006 & $\begin{array}{l}\text { Gobbato, Cataldo } \\
\text { Neto, Gauer }\end{array}$ & $\mathrm{O}$ paciente agressivo & Acta Med. (Porto Alegre) & $27(1)$ \\
\hline 2006 & Itikawa & Vulnerabilidades do trabalho informal de rua & São Paulo Perspect. & $20(1)$ \\
\hline 2006 & Lima & $\begin{array}{l}\text { Mudança das práticas sócio-educativas na FEBEM-SP: as } \\
\text { representaçōes sociais de funcionários }\end{array}$ & Psicol. Soc & $18(1)$ \\
\hline 2006 & Lisboa et al. & $\begin{array}{l}\text { Violência do cotidiano e no trabalho de enfermagem: } \\
\text { apreensōes e expectativas de alunos de um curso de graduação } \\
\text { em enfermagem do Rio de Janeiro }\end{array}$ & $\begin{array}{l}\text { Esc. Anna Nery Rev. } \\
\text { Enferm }\end{array}$ & $10(1)$ \\
\hline
\end{tabular}




\begin{tabular}{|c|c|c|c|c|}
\hline 2006 & $\begin{array}{l}\text { Magalhåes Júnior, } \\
\text { Oliveira }\end{array}$ & $\begin{array}{l}\text { A violência urbana em Belo Horizonte: o olhar da saúde e as } \\
\text { possibilidades de intervenção intersetorial }\end{array}$ & Divulg. Saúde Debate & $1(35)$ \\
\hline 2006 & Martini et al. & $\begin{array}{l}\text { Epidemiology of mandibular fractures treated in a Brazilian } \\
\text { level I Trauma Public Hospital in the city of São Paulo, Brazil }\end{array}$ & Braz. Dent. J & $17(3)$ \\
\hline 2006 & Minayo & Violência, um problema social que afeta a saúde pública & Divulg. Saúde Debate & $1(35)$ \\
\hline 2006 & Nachif & $\begin{array}{l}\text { Homicide as a public health problem in the city of Campo } \\
\text { Grande, Mato Grosso do Sul, Brazil }\end{array}$ & Psicol. Soc & $18(2)$ \\
\hline 2006 & Nascimento & $\begin{array}{l}\text { Educar na convivência: a experiência da Escola Vila, em } \\
\text { Fortaleza }(C E)\end{array}$ & Divulg. Saúde Debate & $1(35)$ \\
\hline 2006 & $\begin{array}{l}\text { Rabelo, Melo, } \\
\text { Campos }\end{array}$ & $\begin{array}{l}\text { Violência e marginalidade na urbe e suas implicaçōes na } \\
\text { infância, adolescência e mulher: Recife (1920-1940) }\end{array}$ & Encontro & $10(13)$ \\
\hline 2006 & $\begin{array}{l}\text { Reichenheim, Dias, } \\
\text { Moraes }\end{array}$ & $\begin{array}{l}\text { Co-ocorrência de violência física conjugal e contra filhos em } \\
\text { serviços de saúde }\end{array}$ & Rev. Saúde Pública & $40(4)$ \\
\hline 2006 & Robazzi et al & $\begin{array}{l}\text { O prontuário hospitalar auxiliando na identificação da } \\
\text { violência no trabalho }\end{array}$ & Rev. Enferm. UERJ & $14(4)$ \\
\hline 2006 & Rocha & $\begin{array}{l}\text { Vidas presas: uma tentativa de compreensão da tragédia da } \\
\text { criminalidade junto às suas personagens prisioneiras }\end{array}$ & Psicol. USP & $17(3)$ \\
\hline 2006 & Scott & $\begin{array}{l}\text { Re-assentamento, saúde e insegurança em Itaparica: um } \\
\text { modelo de vulnerabilidade em projetos de desenvolvimento }\end{array}$ & Saúde Soc & $15(3)$ \\
\hline 2006 & Soares & Segurança pública: presente e futuro & Estud. Av & $20(56)$ \\
\hline 2006 & $\begin{array}{l}\text { Souza, Portinho, } \\
\text { Barreiros }\end{array}$ & $\begin{array}{l}\text { Acidentes de trabalho com óbito registrados em jornais no } \\
\text { estado da Bahia }\end{array}$ & $\begin{array}{l}\text { Rev. Baiana Saúde } \\
\text { Pública }\end{array}$ & $30(1)$ \\
\hline 2006 & Valença, Moraes & Relação entre homicídio e transtornos mentais & Rev. Bras. Psiquiatr & $28(\operatorname{supp} 2)$ \\
\hline 2007 & Abad & El sujeto ante la Ley: violencia y culpa & Rev. Mal-Estar Subj & $7(1)$ \\
\hline 2007 & Adorno, Salla & Criminalidade organizada nas prisôes e os ataques do PCC & Estud. Av & $21(61)$ \\
\hline 2007 & Barroso et al & $\begin{array}{l}\text { Fatores que geram violência no futebol: uma análise } \\
\text { psicológica na regiâo sul do Brasil }\end{array}$ & $\begin{array}{l}\text { Rev. Bras. Cineantropom. } \\
\text { Desempenho Hum; }\end{array}$ & $9(2)$ \\
\hline 2007 & Budó et al. & $\begin{array}{l}\text { Concepçôes de violência e práticas de cuidado dos usuários da } \\
\text { estratégia de saúde da família: uma perspectiva cultural }\end{array}$ & $\begin{array}{l}\text { Texto \& Contexto } \\
\text { Enferm }\end{array}$ & $16(3)$ \\
\hline 2007 & Dantas et al. & $\begin{array}{l}\text { A violência como situação limite nas rodas das cirandas da vida } \\
\text { em Fortaleza, Ceará }\end{array}$ & Divulg. Saúde Debate & $1(39)$ \\
\hline 2007 & Diniz, Santos, Lopes & Social representations of family and violence: [review] & Rev. Latinoam. Enferm & $15(6)$ \\
\hline 2007 & Gawryszeski & Injury mortality report for São Paulo State, 2003 & São Paulo Med. J & $125(3)$ \\
\hline 2007 & Lancman et al & $\begin{array}{l}\text { O trabalho na rua e a exposição à violência no trabalho: um } \\
\text { estudo com agentes de trânsito }\end{array}$ & $\begin{array}{l}\text { Interface Comun. Saúde } \\
\text { Educ; }\end{array}$ & $11(21)$ \\
\hline 2007 & Macedo et al. & $\begin{array}{l}\text { Mudança etiológica do trauma de face de pacientes atendidos } \\
\text { no pronto socorro de cirurgia plástica do Distrito Federal }\end{array}$ & Rev. Soc. Bras. Cir. Plast. & $22(4)$ \\
\hline 2007 & Malta et al. & $\begin{array}{l}\text { A vigilância e prevenção de violências e acidentes no Sistema } \\
\text { Único de Saúde: Uma política em construçâo }\end{array}$ & Divulg. Saúde Debate & $1(39)$ \\
\hline 2007 & Marin-Leon et al. & $\begin{array}{l}\text { Percepção dos problemas da comunidade: influência de fatores } \\
\text { sócio-demográficos e de saúde mental }\end{array}$ & Cad. Saúde Pública & $23(5)$ \\
\hline 2007 & $\begin{array}{l}\text { Matos, Proietti, } \\
\text { Barata }\end{array}$ & $\begin{array}{l}\text { Confiabilidade da informação sobre mortalidade por violência } \\
\text { em Belo Horizonte, MG }\end{array}$ & Rev. Saúde Pública & $41(1)$ \\
\hline 2007 & Mesquita, Mello & $\begin{array}{l}\text { Características da morbidade por causas externas em serviço } \\
\text { de urgência }\end{array}$ & Rev. Bras. Epidemiol & $10(4)$ \\
\hline
\end{tabular}




\begin{tabular}{|c|c|c|c|c|}
\hline 2007 & Misse & $\begin{array}{l}\text { Mercados ilegais, redes de proteçãa e organização local do } \\
\text { crime no Rio de Janeiro }\end{array}$ & Estud. Av & $21(61)$ \\
\hline 2007 & Pereira et al. & $\begin{array}{l}\text { Produção sobre acidentes e violência apresentada em encontros } \\
\text { de iniciação científica }\end{array}$ & Rev. Enferm. UERJ & $15(2)$ \\
\hline 2007 & Ramos & $\begin{array}{l}\text { A imagem, o som e a fúria: a representaçáo da violência no } \\
\text { documentário brasileiro }\end{array}$ & Estud. Av & $21(61)$ \\
\hline 2007 & Rosa, Malta, Lopés & $\begin{array}{l}\text { Terapia comunitária: uma prática que empodera o coletivo } \\
\text { para uma cultura de paz no município de Santo Antônio de } \\
\text { Jesuz, Bahia }\end{array}$ & Divulg. Saúde Debate & $1(39)$ \\
\hline 2007 & Sá, Werlang & Homicídio seguido de suicídio na cidade de Porto Alegre & Estud. Psicol. (Campinas) & $24(2)$ \\
\hline 2007 & Schroder et al. & Violência contra o médico & Acta Med. (Porto Alegre) & $28(1)$ \\
\hline 2007 & $\begin{array}{l}\text { Silva, Coelho, } \\
\text { Caponi. }\end{array}$ & $\begin{array}{l}\text { Violência silenciosa: violência psicológica como condição da } \\
\text { violência física doméstica }\end{array}$ & $\begin{array}{l}\text { Interface Comun. Saude } \\
\text { Educ; }\end{array}$ & $11(21)$ \\
\hline 2007 & Souza et al. & $\begin{array}{l}\text { Peculiaridades do controle da tuberculose em um cenário de } \\
\text { violência urbana de uma comunidade carente do Rio de Janeiro }\end{array}$ & J. Bras. Pneumol & $33(3)$ \\
\hline 2007 & Souza, Santana & $\begin{array}{l}\text { Concepçôes de enfermeiros gestores municipais de saúde sobre } \\
\text { a violência }\end{array}$ & Rev. Enferm. UERJ & $15(1)$ \\
\hline 2007 & $\begin{array}{l}\text { Vianna, Oliveira, } \\
\text { Espírito Santo }\end{array}$ & $\begin{array}{l}\text { Populaçốes excluídas exercitando a cidadania ativa: a } \\
\text { experiência da Agenda Redutora da Violência na comunidade } \\
\text { de Manguinhos, Rio de Janeiro }\end{array}$ & Divulg. Saude Debate & $1(39)$ \\
\hline 2007 & Waiselfisz & Mapa das mortes por violência & Estud. Av & $21(61)$ \\
\hline 2007 & Zaluar & Democratização inacabada: fracasso da segurança pública & Estud. Av & $21(61)$ \\
\hline
\end{tabular}


Violence and health: an analysis of the scientific production in national journals from 2003 to 2007

Violence is nowadays understood as one of the largest public health problems worldwide, whose magnitude grows vertiginously, and is subject of discussion and interventions that in the media in general, as in academic publications. Considering the increasing speed of production and spread of scientific knowledge and the need to discuss the phenomenon in the Brazilian reality, we intended to analyze the scientific production published in national health journals about violence and health matters from 2003 to 2007. Data were collected from Lilacs database and organized in a protocol in which the study variables were inserted. The process of data analyses was conducted through descriptive statistics and content analyses used the theme modality, attesting the pulverization of studies on violence in health journals, mainly in those concerned with public health. Based on different kinds of approaches, the authors were concerned with the study of themes related to theoretical-methodological constructions; violence and gender; violence and childhood; violence against the elderly; violence in specific contexts, violence and the world of work. It was possible to identify, in the period studied, gaps in knowledge production on health about violence against especially vulnerable groups, as well as the analysis of the effectiveness of strategies to fight this situation.

Key words: violence; health; evaluation health's research. 